OPEN ACCESS

Edited by:

Raymond J. Turner,

University of Calgary, Canada

Reviewed by:

Thomas Maskow,

Helmholtz-Zentrum für

Umweltforschung,

Helmholtz-Gemeinschaft Deutscher

Forschungszentren (HZ), Germany

Tim Magnuson,

Idaho State University, United States

*Correspondence:

Felipe Arenas

felipe.arenass@usach.c

Specialty section:

This article was submitted to Microbiotechnology, Ecotoxicology and Bioremediation,

a section of the journal

Frontiers in Microbiology

Received: 05 August 2018 Accepted: 03 December 2018 Published: 18 December 2018

Citation:

Contreras $F$, Vargas $E$, Jiménez $K$, Muñoz-Villagrán C, Figueroa $M$, Vásquez C and Arenas F (2018) Reduction of Gold (III) and Tellurium (IV) by Enterobacter cloacae MF01 Results in Nanostructure Formation

Both in Aerobic and Anaerobic Conditions. Front. Microbiol. 9:3118. doi: 10.3389/fmicb.2018.03118

\section{Reduction of Gold (III) and Tellurium (IV) by Enterobacter cloacae MF01 Results in Nanostructure Formation Both in Aerobic and Anaerobic Conditions}

Fernanda Contreras' ${ }^{1}$ Esteban Vargas², Karla Jiménez¹, Claudia Muñoz-Villagrán ${ }^{1,3}$, Maximiliano Figueroa ${ }^{1}$, Claudio Vásquez ${ }^{1}$ and Felipe Arenas ${ }^{1 *}$

${ }^{1}$ Laboratorio Microbiología Molecular, Departamento de Biología, Facultad de Química y Biología, Universidad de Santiago de Chile, Santiago, Chile, ${ }^{2}$ Center for the Development of Nanoscience and Nanotechnology, Santiago, Chile,

${ }^{3}$ Departamento de Ciencias Básicas, Facultad de Ciencias, Universidad Santo Tomás, Santiago, Chile

Microorganism survival in the presence of toxic substances such as metal(loid)s lies chiefly on their ability to resist (or tolerate) such elements through specific resistance mechanisms. Among them, toxicant reduction has attracted the attention of researchers because metal(loid)-reducing bacteria are being used to recover and/or decontaminate polluted sites. Particularly, our interest is to analyze the toxicity of gold and tellurium compounds for the environmental microorganism Enterobacter cloacae MF01 and also to explore the generation of nanostructures to be used in future biotechnological processes. Resistance of E. cloacae MF01 to gold and tellurium salts as well as the putative mechanisms involved -both in aerobic and anaerobic growth conditions- was evaluated. These metal(loid)s were selected because of their potential application in biotechnology. Resistance to auric tetrachloride acid $\left(\mathrm{HAuCl}_{4}\right)$ and potassium tellurite $\left(\mathrm{K}_{2} \mathrm{TeO}_{3}\right)$ was assessed by determining areas of growth inhibition, minimum inhibitory concentrations, and growth curves as well as by viability tests. E. cloacae MF01 exhibited higher resistance to $\mathrm{HAuCl}_{4}$ and $\mathrm{K}_{2} \mathrm{TeO}_{3}$ under aerobic and anaerobic conditions, respectively. In general, their toxicity is mediated by the generation of reactive oxygen species and by a decrease of intracellular reduced thiols (RSH). To assess if resistance implies toxicant reduction, intra- and extra-cellular toxicant-reducing activities were evaluated. While E. cloacae MF01 exhibited intra- and extra-cellular $\mathrm{HAuCl}_{4}$-reducing activity, tellurite reduction was observed only intracellularly. Then, Auand Te-containing nanostructures (AuNS and TeNS, respectively) were synthesized using crude extracts from E. cloacae MF01 and their size, morphology, and chemical composition was evaluated.

Keywords: metal(loid)s, Enterobacter cloacae, metal(loid) resistance, EPS, reduction, aerobiosis, anaerobiosis, nanostructures 


\section{INTRODUCTION}

Although most of the dry weight of a living cell is composed by elements such as $\mathrm{C}, \mathrm{O}, \mathrm{H}, \mathrm{N}, \mathrm{P}$ and $\mathrm{S}$, there are other elements that are required to sustain independent life (Nies and Silver, 1995). Among them, some metal(loid)s fulfill cellular functions that cannot be carried out by organic molecules, thus being crucial for the structure of cell membranes, DNA and proteins; they also participate in a number of key cellular processes such as electron transfer and catalysis (Lemire et al., 2013). Nevertheless, there are other metal(loid)s for which there is no known biological function to date (Nies, 1999; Harrison et al., 2004). These include gold $\left(\mathrm{Au}^{3+}\right)$, mercury $\left(\mathrm{Hg}^{2+}\right)$, cadmium $\left(\mathrm{Cd}^{2+}\right)$ and tellurium $\left(\mathrm{Te}^{4+}, \mathrm{Te}^{6+}\right)$, which are extremely toxic to organisms even at very low concentrations (Nies, 1999; Taylor, 1999; Pérez et al., 2007; Zannoni et al., 2007; Lemire et al., 2013). Despite their toxicity, the interest in these elements has grown the last few years because of its applicability in the medical, metallurgical, chemical, and optical industry (Bao et al., 2010).

In general terms, under aerobic conditions metal(loid) toxicity is due -at least in part- to the increased generation of intracellular reactive oxygen species (ROS), which can affect a number of key metabolic pathways generating: (i) protein and enzyme dysfunction, oxidation of catalytic residues and [Fe-S] cluster dismantling (Stadtman and Levine, 2000; Helbig et al., 2008); (ii) single or double breaks in DNA (Imlay et al., 1988; Touati et al., 1995); (iii) lipid peroxidation of cell membranes (Hong et al., 2012; Lemire et al., 2013), among others. Since ROS are formed only in aerobic conditions (Imlay, 2003), the observed toxicant damage in anaerobiosis should be independent of ROS.

Microbes have evolved a number of strategies to thrive in the presence of these toxic metal(loid)s, which are rather specific: no common resistance strategy has been described to date (Lemire et al., 2013). The referred strategies include: (i) decreased uptake or enhanced efflux of metal ions because of changes in the activity or production of membrane transport proteins (Ma et al., 2009); (ii) intra- or extra-cellular sequestration, mediated mainly by polymers or siderophores that can trap or precipitate metal ions (Harrison et al., 2007; Zannoni et al., 2007; Dimkpa et al., 2008); (iii) chaperone-, enzyme- or antioxidants-mediated repair of molecules that are prone to oxidation by metals; (iv) metabolic bypass, by which an alternative metabolic pathway is generated to cope with the metal ion (Lemire et al., 2010) and finally, (v) chemical modification of the toxicant, that usually converts the metal(loid) into a less toxic (or less available) form (Silver and Phung, 1996, 2005).

The phenomenon of metal(loid) reduction has also been observed in vitro using crude cell extracts or purified proteins. In this frame, a number of enzymes involved in metal(loid) tolerance have been identified which, apart from their normal metabolic functions can help in the process of metal reduction. In particular, some of them belong to the flavoprotein family (Heuts et al., 2009) including the E3 component of the multienzyme pyruvate dehydrogenase complex of Escherichia coli and other microorganisms (Castro et al., 2008), NDH-II of E. coli (Díaz-Vásquez et al., 2015), thioredoxin reductase (Trx) and alkyl hydroperoxide reductase (AhpF) of Staphylococcus haemolyticus BNF01 (Arenas-Salinas et al., 2016) and glutathione reductase (GorA) from E. coli; all of them can generate reduced, elemental tellurium while GorA also produces metallic gold from tetrachloroauric acid reduction (Pugin et al., 2014; Figueroa et al., 2018).

On the other hand, other groups have suggested that extracellular polymeric substances (EPSs) could also participate in metal(loid) reduction (Smith and Gadd, 2000; Dohnalkova et al., 2005; Harish et al., 2012). EPS can be defined as a matrix that forms part of the bacterial cell surface which is composed by a variety of macromolecules including polysaccharides, proteins, nucleic acids, phospholipids, and other low molecular weight components (Wingender et al., 1999). The mechanism(s) of EPS-mediated metal(loid) reduction has been hard to determine because EPS constituents vary greatly among microorganisms (Pal and Paul, 2008).

Microorganisms can remediate metal(oid)s because of their ability to change the compound's oxidation state, influencing their solubility that results in the formation of less toxic and often insoluble derivatives (Suresh, 2012). In some cases, these represent metallic, nanoscaled arrangements generically known as nanostructures (NS). Reports on tellurium (Arenas-Salinas et al., 2016) and gold (Correa-Llantén et al., 2013) nanostructures synthesized by E. coli and Geobacillus sp., respectively, have generated great interest due to its potential application in the field of biotechnology. Nanostructure production by biological methods is considered a safe, economical and environmentally friendly process, in contrast to chemical procedures that require high temperatures, anaerobic conditions and/or the presence of a number of toxic components (Turner et al., 2012).

The specific, mechanical, optical and fluorescence properties exhibited by metal(loid)-containing nanostructures makes them excellent candidates to be used in the field of physics, chemistry, electronics, materials science, biomedicine, electronics and agriculture, among others (Thakkar et al., 2010). Particularly interesting is the field of biomedicine, where NS have been used in therapies to detect cancer (Rao, 2008) and as antibacterials (Amstad et al., 2011; Azam et al., 2012). In this line, nanostructures with bactericidal (Cui et al., 2012; Xiu et al., 2012; Pugin et al., 2014; Oves et al., 2017) as well as antibacterial activity have been reported (Cioffi and Rai, 2012).

Summarizing, it is of great interest to unveil the mechanism by which microorganisms are able to tolerate metal(loid) since it could involve the reduction of these elements to less toxic forms. In this line, this work describes the generation of Auand Te-containing NS by Enterobacter cloacae MF01 which could represent interesting candidates for biotechnological processes.

\section{MATERIALS AND METHODS}

\section{Bacterial Isolation and Growth Conditions}

Enterobacter cloacae MF01 was isolated from environmental water samples from central Chile (Cascada Invertida, Maule Region; Figueroa et al., 2018). The bacterium was grown in LB medium with shaking at $150 \mathrm{rpm}$ at $37^{\circ} \mathrm{C}$ both in aerobic or 
anaerobic conditions $\left(100 \% \mathrm{~N}_{2}\right.$, Coy chamber, Coy Laboratory Products, Inc.). Growth in solid media was carried out in $2 \%$ $(w / v)$ LB agar plates.

\section{Determination of the Growth Inhibition Area}

One hundred $\mu \mathrm{L}$ of cells grown to stationary growth phase were evenly spread on LB agar plates. After drying briefly in air, three sterile filter paper disks $(0.6 \mathrm{~cm}$ diameter $)$ were placed on each plate, to which $10 \mu \mathrm{L}$ of the toxican to be tested were added: $50 \mathrm{mM}$ auric tetrachloride acid $\left(\mathrm{HAuCl}_{4}\right)$ or $4 \mathrm{mM}$ potassium tellurite $\left(\mathrm{K}_{2} \mathrm{TeO}_{3}\right)$. The zone of growth inhibition $\left(\mathrm{cm}^{2}\right)$ was determined after incubating the plates at $37^{\circ} \mathrm{C}$ for $24 \mathrm{~h}$.

\section{Determination of the Minimal Inhibitory Concentration (MIC)}

Serial dilutions (1:2) were made from sterile solutions of $\mathrm{HAuCl}_{4}$ and $\mathrm{K}_{2} \mathrm{TeO}_{3}$ in $1 \mathrm{~mL}$ of $\mathrm{LB}$ medium in 48 -well culture plates. Subsequently, $10 \mu \mathrm{L}$ of $E$. cloacae MF01 cultures grown in LB up to $\mathrm{OD}_{600} 0.6$ (aerobic conditions) or 0.4 (anaerobic conditions) were added to each well and incubation proceeded with constant shaking at $37^{\circ} \mathrm{C}$. Minimal inhibitory concentrations (MICs) were determined by monitoring turbidity at $600 \mathrm{~nm}$ after $24 \mathrm{~h}$.

\section{Curves and Growth Parameters}

Overnight cultures were diluted 1:100 with fresh LB medium and incubated at $37^{\circ} \mathrm{C}$ to $\mathrm{OD}_{600} \sim 0.6$ (aerobiosis) or 0.4 (anaerobiosis). Then, $10 \mu \mathrm{L}$ were added to $1 \mathrm{~mL}$ of fresh $\mathrm{LB}$ medium containing sublethal concentrations of each metal(loid) in 48 -well plates. Growth was monitored at $600 \mathrm{~nm}$ every $30 \mathrm{~min}$ at $37^{\circ} \mathrm{C}$ for $15 \mathrm{~h}$ in a TECAN Infinite ${ }^{\circledast} \mathrm{M} 200$ plate reader.

Data were plotted and growth parameters corresponding to the maximum $\mathrm{OD}_{600}(\%)$, lag phase duration $(\mathrm{h})$, growth rate $(\mu)$ and generation time $(h)$ were determined. The maximum $\mathrm{OD}_{600}$ reached by the culture was referred to that of the control $(100 \%)$. The duration of the lag phase was determined as the end point of the latency phase and beginning of the exponential phase of bacterial growth. The growth rate was estimated as the change in the $\mathrm{OD}_{600}$ per h during the exponential growth phase. Finally, the generation time was calculated from the equation $\mathrm{g}=0.693 / \mu$.

\section{Bacterial Viability Assays}

Overnight cultures of $E$. cloacae MF01 were diluted 1:100 with fresh $\mathrm{LB}$ medium and incubated at $37^{\circ} \mathrm{C}$ and $150 \mathrm{rpm}$ to $\mathrm{OD}_{600}$ 0.6 (aerobic) or 0.4 (anaerobic). Subsequently, $180 \mu \mathrm{L}$ aliquots of the cultures were added to $20 \mu \mathrm{L}$ of fresh $\mathrm{LB}$ medium containing different concentrations of the toxicants in 96 well plates (0$38 \mathrm{mM} \mathrm{HAuCl}_{4}, 0-60 \mathrm{mM} \mathrm{K}_{2} \mathrm{TeO}_{3}$ ). After $15 \mathrm{~min}$, aliquots of $20 \mu \mathrm{L}$ were taken and added to a 96-well plate containing $180 \mu \mathrm{L}$ of $0.9 \% \mathrm{NaCl}$. Serial dilutions (1:10) were made in the 96-well plate, from which $4 \mu \mathrm{L}$ were seeded in LB agar plates (drop). The number of colony forming units (CFUs) was determined after incubating at $37^{\circ} \mathrm{C}$ for $24 \mathrm{~h}$.

\section{Detection of Total Reactive Oxygen Species (Total ROS)}

Intracellular total ROS levels in cells exposed to $\mathrm{HAuCl}_{4}$ or $\mathrm{K}_{2} \mathrm{TeO}_{3}$ were determined using $2^{\prime}, 7^{\prime}$-dichlorodihydrofluorescein diacetate as probe $\left(\mathrm{H}_{2} \mathrm{DCFDA}\right.$, Calbiochem). Overnight E. cloacae MF01 cultures were diluted 1:100 with fresh LB medium and incubated at $37^{\circ} \mathrm{C}$ with shaking to $\mathrm{OD}_{600} \sim 0.6$ (aerobic) or $\sim 0.4$ (anaerobic). Then, cells were treated with the toxicants ( $0.5 \mathrm{x}$ of the corresponding MIC) and with ascorbic acid $(10 \mathrm{mM})$. One $\mathrm{mL}$ aliquots were taken at different times $(0,15$, and $120 \mathrm{~min})$ and sedimented at $12,000 \times g$ for $5 \mathrm{~min}$. Pellets were washed three times with $50 \mathrm{mM}$ Tris- $\mathrm{HCl}$ buffer $\mathrm{pH} 7.4$ and subsequently, $50 \mu \mathrm{L}$ were added to $930 \mu \mathrm{L}$ of $50 \mathrm{mM}$ Tris- $\mathrm{HCl}$ buffer $\mathrm{pH}$ 7.4, treated with $\mathrm{H}_{2}$ DCFDA $(40 \mu \mathrm{M}$, prepared in dimethyl sulfoxide) and incubated in the dark for $30 \mathrm{~min}$. Cells were centrifuged as above for $5 \mathrm{~min}$ and washed with $50 \mathrm{mM}$ Tris- $\mathrm{HCl}$ buffer $\mathrm{pH}$ 7.4. Finally, $200 \mu \mathrm{L}$ of the cell suspension were used to determine fluorescence intensity in a Tecan Infinite ${ }^{\circledast}$ M200 Pro plate multi lector (excitation $490 \mathrm{~nm}$, emission $527 \mathrm{~nm}$ ). Fluorescence intensity was normalized by $\mathrm{OD}_{600}$. Per cent of fluorescence intensity regarding that of the control condition (100\%) was calculated.

\section{Determination of the Reduced Cellular Thiol (RSH) Concentration}

Overnight cultures of $E$. cloacae MF01 were diluted 1:100 with fresh $\mathrm{LB}$ medium and incubated at $37^{\circ} \mathrm{C}$ to $\sim \mathrm{OD}_{600} 0.6$ (aerobic) or 0.4 (anaerobic). Cultures were treated with the toxicants as above and then aliquots of $500 \mu \mathrm{L}$ were taken at different times $(0,15 \mathrm{~min}$ and $24 \mathrm{~h})$ and sedimented at $12,000 \times g$ for $2 \mathrm{~min}$. Sediments were suspended in $1 \mathrm{~mL}$ of $5 \mathrm{mM}$ EDTA, $0.1 \%$ SDS, $0.1 \mathrm{mM}$ DTNB and $50 \mathrm{mM}$ Tris-HCl buffer $\mathrm{pH}$ 8.0. The suspension was incubated for $30 \mathrm{~min}$ at $37^{\circ} \mathrm{C}$ and subsequently, vigorously shaken and sedimented at $12,000 \times g$ for $10 \mathrm{~min}$. Finally, the supernatant was rescued and the absorbance at $412 \mathrm{~nm}$ measured in a Tecan Infinite ${ }^{\circledR}$ M200 Pro plate multireader. The RSH content was calculated through a calibration curve constructed with GSH standards $(0-200 \mu \mathrm{M})$. RSH concentration was normalized by protein concentration. Per cent of RSH was calculated with respect to the respective control condition (100\%).

\section{Protein Concentration}

Protein concentration was determined by the method described by Bradford (1976) using bovine serum albumin (BSA) as standard.

\section{Determination of Gold and Tellurium Total Content by Optical Emission Spectroscopy - Inductively Coupled Plasma (ICP-OES)}

Enterobacter cloacae was grown to $\mathrm{OD}_{600} \sim 0.6$ (aerobic) or 0.4 (anaerobic), treated with the toxicants as above for $15 \mathrm{~min}$ and centrifuged at $12,000 \times g$ for $4 \mathrm{~min}$ at $4^{\circ} \mathrm{C}$. After storing the supernatant, the sediment was suspended in $50 \mathrm{mM}$ Tris- $\mathrm{HCl}$ 
pH 7.4 buffer supplemented with $0.1 \mathrm{mM}$ phenylmethylsulfonyl fluoride (PMSF, Life Technologies, Inc.). After sonicating on ice (four pulses of $20 \mathrm{~s}$ each), the cell debris was removed by centrifugation $(21,000 \times g)$ for $10 \mathrm{~min}$ at $4^{\circ} \mathrm{C}$. The supernatant was ultracentrifuged at $120,000 \times g$ for $1 \mathrm{~h}$ in a Beckman optima LE-80K centrifuge using a $70.1 \mathrm{Ti}$ rotor. This new supernatant was considered the crude extract while the sediment represented the membrane fraction.

Supernatants, intracellular and membrane fractions from cells exposed to the toxicants were diluted with $\mathrm{HNO}_{3}$ (up to 2\%), filtered (0.22 $\mu \mathrm{m}$ nylon filters, GE Healthcare, Life Sciences) and used for determining gold and tellurium in a PerkinElmer Optima 2000 DV ICP-OES device. Calibration curves were made with gold and tellurium commercial standards. Per cent of gold and tellurium was calculated regarding the respective controls (100\%, aerobic and anaerobic).

\section{Metal(loid)-Reducing Activity by Crude Extracts}

$\mathrm{HAuCl}_{4}$ and $\mathrm{K}_{2} \mathrm{TeO}_{3}$ reducing activities were assessed at $37^{\circ} \mathrm{C}$ using $20 \mathrm{mM}$ potassium phosphate ( $\mathrm{pH}$ 6.0-7.0) and $50 \mathrm{mM}$ Tris$\mathrm{HCl}$ ( $\mathrm{pH} 8.0-9.0$ ) buffers, respectively. Generation of metallic gold and tellurium was monitored in a TECAN Infinite M200 Pro multimode plate reader at $500 \mathrm{~nm}$ (Te, Pugin et al., 2014) and $540 \mathrm{~nm}$ (Au, Correa-Llantén et al., 2013). Reactions were carried out in a final volume of $200 \mu \mathrm{L}$ that contained the appropriate buffer, $1 \mathrm{mM} \mathrm{HAuCl}_{4}$ or $\mathrm{K}_{2} \mathrm{TeO}_{3}, 1 \mathrm{mM} \mathrm{NADH}$ or NADPH and the crude extract. Controls excluding extracts were run in each case to rule out abiotic reduction. For tellurite reduction, the reaction mix also contained $1 \mathrm{mM} \beta$-mercaptoethanol. An enzyme unit (U) was defined as the amount of enzyme that increased the absorbance by 0.001 units in 1 min under the assay conditions. The enzymatic activity was normalized by the protein concentration.

\section{Purification of Extracellular Polymeric Substances (EPSs)}

Purification of bacterial EPS was accomplished by using the modified cold ethanol precipitation method described by Bramhachari and Dubey (2006). Cells of E. cloacae MF01 were grown to stationary phase and centrifuged at $4^{\circ} \mathrm{C}$. Supernatants were filtered under vacuum using a $0.45 \mu \mathrm{m}$ nitrocellulose filter (Merck Millipore). EPS were precipitated by adding three volumes of cold ethanol to the filtrate. After incubating at $4^{\circ} \mathrm{C}$, the sample was sedimented at $12,000 \times g$ for $10 \mathrm{~min}$ at $4^{\circ} \mathrm{C}$ and washed three times with $70 \%$ ethanol. EPS were dissolved in $2 \mathrm{~mL}$ of miliQ water and dialyzed for $24 \mathrm{~h}$ at $4^{\circ} \mathrm{C}$ against nanopure water (dialysis membrane $12-14 \mathrm{kDa}$ MW cut-off, Spectra/Por ${ }^{\circledR}$ ).

\section{EPS Analysis}

Total sugar content in EPS was estimated using the modified UVsulfuric acid method of Albalasmeh et al. (2013). Briefly, $300 \mu \mathrm{L}$ of EPS solution were mixed with $1 \mathrm{~mL}$ of concentrated $\mathrm{H}_{2} \mathrm{SO}_{4}$. The mixture was cooled on ice for $2 \mathrm{~min}$ and the production of furfural derivatives was monitored at $315 \mathrm{~nm}$. A D-glucose calibration curve was used as standard. Protein content was determined as described in Section "Materials and Methods."

\section{E. cloacae EPS-Mediated Metal(loid) Reducing Activity}

Extracellular polymeric substance-mediated metal(loid) reducing activity was assessed as specified in Section "Metal(loid)Reducing Activity by Crude Extracts." The reaction was carried out in a final volume of $200 \mu \mathrm{L}$ that contained the appropriate buffer, $1 \mathrm{mM} \mathrm{HAuCl}_{4}$ or $\mathrm{K}_{2} \mathrm{TeO}_{3}, 5 \mathrm{mg} / \mathrm{mL} \mathrm{BPN}$ subtilisin (Sigma) or $1 \mathrm{U} / \mu \mathrm{L}$ benzonase nuclease (Novagen) and $10 \mu \mathrm{L}$ of the purified EPS. Controls to rule out abiotic reduction were run in each case. Reducing activities of $\mathrm{HAuCl}_{4}$ or $\mathrm{K}_{2} \mathrm{TeO}_{3}$ were defined as the difference in absorbance after incubation at $37^{\circ} \mathrm{C}$ for $24 \mathrm{~h}$ at 540 or $500 \mathrm{~nm}$, respectively.

\section{Analysis of EPS by Scanning Electron Microcopy}

To confirm the formation of exopolysaccharide material after toxicant exposure, cultures of E. cloacae MF01 were treated with $8 \mu \mathrm{M} \mathrm{K}_{2} \mathrm{TeO}_{3}(0.5 \mathrm{x}$ the $\mathrm{MIC}$ in aerobic conditions) and incubated at $37^{\circ} \mathrm{C}$ for $24 \mathrm{~h}$. After plating on LB agar plates, incubation was continued under the same conditions for $24 \mathrm{~h}$. Samples were fixed by mild heating in glass covers and then dried for later visualization. Prior to imaging, samples were stained, mounted on conductive adhesive and sputter coated with gold film. Electron microscopy analysis was performed using a SEM Zeiss EVO MA-10 equipment and imaged at an accelerating voltage of $20 \mathrm{kV}$ and $8 \mathrm{~mm}$ of working distance. This study was conducted at the Center for the Development of Nanoscience and Nanotechnology - CEDENNA, Universidad de Santiago de Chile (USACH).

\section{In vitro Synthesis of Nanostructures}

Crude extracts from E. cloacae MF01 (200 $\mu \mathrm{g} / \mathrm{mL}$ protein) were used to produce nanostructures by incubation with $1 \mathrm{mM}$ $\mathrm{HAuCl}_{4}$ or $\mathrm{K}_{2} \mathrm{TeO}_{3}$ for $24 \mathrm{~h}$ at the optimal conditions of temperature, $\mathrm{pH}$, cofactor, and growth conditions (as determined from reduction assays) in a final volume of $1 \mathrm{~mL}$. Controls to rule out abiotic synthesis were run in each case. Concentrations of these nanostructures were calculated by dry weight, which was expressed as $\mu \mathrm{g} / \mathrm{ml}$.

\section{Analysis of Nanostructures by Transmision Electron Microscopy}

The morphology of the synthesized nanostructures was analyzed by TEM using a Hitachi Transmission Electron Microscope HT7700 (CEDENNA, USACH). To do this, a drop of the synthesized nanostructures was placed on a copper grid and analyzed briefly after.

\section{Energy Dispersive X-ray Spectroscopy (EDS)}

Energy dispersive X-ray spectroscopy (EDS) analysis was carried out to determine the chemical composition of the synthesized 
nanostructures. Samples were analyzed by scanning electron microscopy (SEM) using a Zeiss EVO MA-10 microscope with a tungsten filament gun and by EDX spectra which were collected using an Oxford Instruments X-act system attached to a microscope equipped with a Penta FET Precision detector (CEDENNA, USACH). Prior to imaging, samples were supported on glass slides and stained with Gram-Hucker kit, fixed on conductive adhesive over pin stub mount and sputter coated with gold film to protect the surface from damage and calcinations and to minimize charge related artifacts. The samples were imaged at an accelerating voltage of $20 \mathrm{kV}$ and $8 \mathrm{~mm}$ of working distance.

\section{Data Analysis}

Plots and statistical analyses were carried out using the GraphPad Prism 7.0 (GraphPad Software, Inc.). Analysis of variance (ANOVA) and $t$-test were used considering $p<0.05$. The statistical significance was indicated as follows: ${ }^{*} p<0.05$, ${ }^{* *} p<0.01,{ }^{* * *} p<0.001$, and ${ }^{* * * *} p<0.0001$; ns, not significant.

\section{RESULTS}

\section{Metal(loid) Resistance in E. cloacae MF01}

Minimal inhibitory concentrations of $\mathrm{HAuCl}_{4}$ and $\mathrm{K}_{2} \mathrm{TeO}_{3}$ for E. cloacae MF01 both under aerobic and anaerobic conditions were determined. Under aerobic conditions, the $\mathrm{MIC}$ of $\mathrm{HAuCl}_{4}$ was twice that in the absence of oxygen ( 0.50 vs. $0.25 \mathrm{mM}$ ), thus suggesting that the anaerobic condition makes the isolate more sensitive to the toxicant. Conversely, $\mathrm{TeO}_{3}^{2-}$ was more toxic for $E$. cloacae MF01 in aerobic growth conditions (0.016 vs. 0 . $031 \mathrm{mM})$.

Supplementary Figure S1 shows the areas of growth inhibition of E. cloacae $\mathrm{MF01}$ exposed to $\mathrm{HAuCl}_{4}$ or $\mathrm{K}_{2} \mathrm{TeO}_{3}$ under aerobic and anaerobic growth conditions. While the bacterium grew better in the presence of $\mathrm{HAuCl}_{4}$ in aerobiosis, it turned to be more resistant to tellurite in the anaerobic condition.

The effect of sublethal concentrations of $\mathrm{HAuCl}_{4}$ and $\mathrm{K}_{2} \mathrm{TeO}_{3}$ on E. cloacae MF01 growth was evaluated in aerobiosis and anaerobiosis (Figure 1). The bacterium showed less and slower growth -irrespective of the presence of oxygen- than the respective controls in the presence of $\mathrm{HAuCl}_{4}(15.6$ and $7.8 \mu \mathrm{M}$, Figures 1A,B) or $\mathrm{K}_{2} \mathrm{TeO}_{3}(0.98$ and $0.49 \mu \mathrm{M}$, Figures 1 C,D).

The variation of $E$. cloacae growth parameters when exposed to $\mathrm{HAuCl}_{4}$ or $\mathrm{K}_{2} \mathrm{TeO}_{3}$ was quantified (Supplementary Table S1). When cells were exposed to defined $\mathrm{HAuCl}_{4}$ or $\mathrm{K}_{2} \mathrm{TeO}_{3}$ concentrations, the maximal $\mathrm{OD}_{600}$ was always higher in aerobic conditions (Figure 1 and Supplementary Table S1). Lag phase duration in the presence of $\mathrm{HAuCl}_{4}$ was lower in anaerobic conditions while the opposite situation was observed upon tellurite exposure (Supplementary Table S1). In turn, in the presence of either toxicant the growth rate showed a trend to be higher in the aerobic condition. A similar result was observed when generation time was calculated, i.e., E. cloacae MF01 exposed to $\mathrm{HAuCl}_{4}$ or $\mathrm{K}_{2} \mathrm{TeO}_{3}$ exhibited a shorter generation time in aerobiosis (Supplementary Table S1).

\section{A}

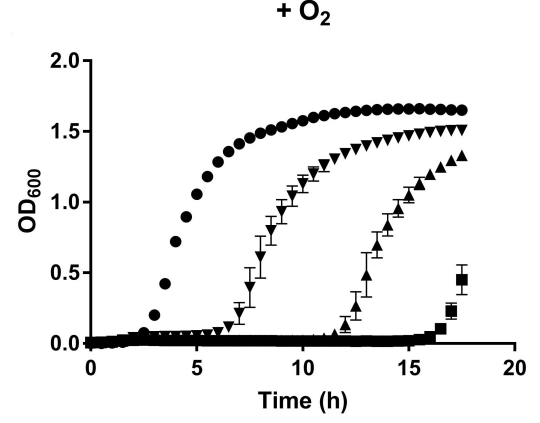

C

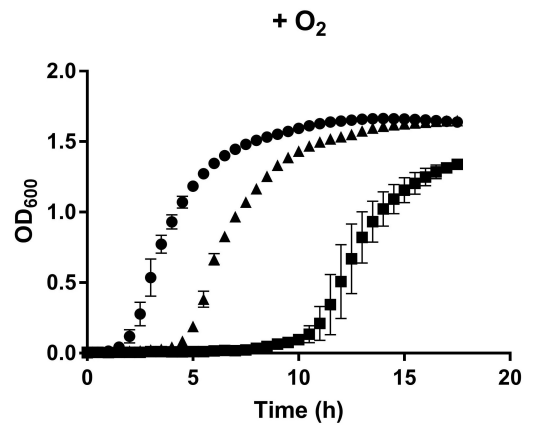

B

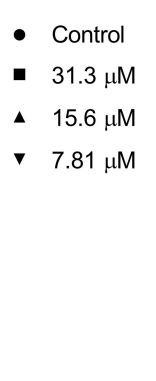

- Control

- $15.6 \mu \mathrm{M}$

$7.81 \mu \mathrm{M}$

ำ

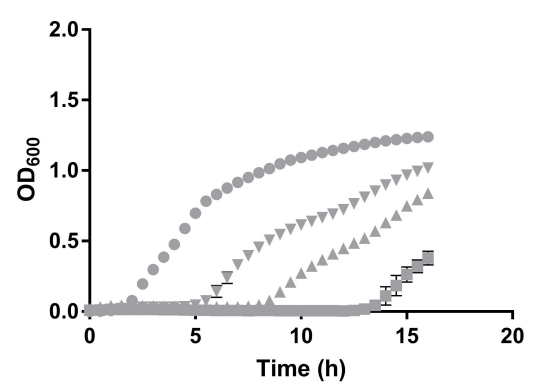

- Control

- $31.3 \mu \mathrm{M}$

- $15.6 \mu \mathrm{M}$

v $7.81 \mu \mathrm{M}$

D

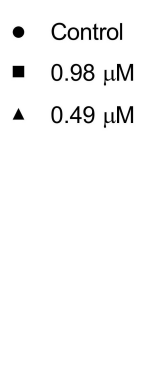

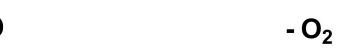

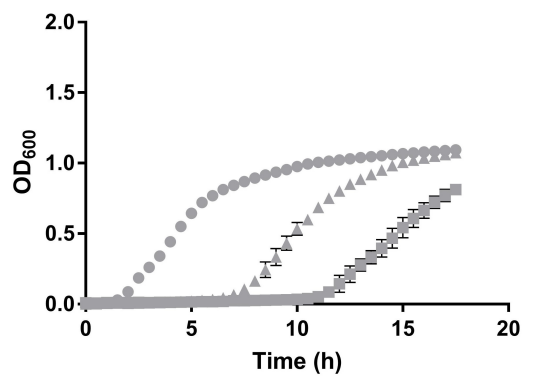

- Control

- $0.98 \mu \mathrm{M}$

- $0.49 \mu \mathrm{M}$

FIGURE 1 | Growth curves of Enterobacter cloacae MF01 exposed to sublethal concentrations of $\mathrm{HAuCl}_{4} \mathrm{Or} \mathrm{K}_{2} \mathrm{TeO}_{3}$ under aerobic and anaerobic conditions. Cells were grown in $\mathrm{LB}$ medium in the absence or presence of $\mathrm{HAuCl}_{4} \mathbf{( A , B )}$ or $\mathrm{K}_{2} \mathrm{TeO}_{3} \mathbf{( C , D )}$ both under aerobic $(\mathbf{A}-\mathbf{C})$ and anaerobic conditions (B,D). Each point corresponds to the average of six independent tests \pm SD. 
Viability tests of E. cloacae MF01 exposed to defined concentrations of $\mathrm{HAuCl}_{4}$ or $\mathrm{K}_{2} \mathrm{TeO}_{3}$ for $15 \mathrm{~min}$ in aerobiosis or anaerobiosis showed that the bacterium tolerates higher toxicant concentrations in the presence of oxygen. The aerobic $\mathrm{LC}_{50}$ of $\mathrm{HAuCl}_{4}$ and $\mathrm{K}_{2} \mathrm{TeO}_{3}$ was $5.9 \pm 1.084$ and $5.1 \pm 1.09 \mathrm{mM}$, respectively, while under anaerobic conditions the $\mathrm{LC}_{50}$ of $\mathrm{HAuCl}_{4}$ and $\mathrm{K}_{2} \mathrm{TeO}_{3}$ was $4.8 \pm 1.048$ and $0.50 \pm 0.102 \mathrm{mM}$, respectively.

\section{Toxicity of $\mathrm{HAuCl}_{4}$ and $\mathrm{K}_{2} \mathrm{TeO}_{3}$ for E. cloacae MF01}

Total ROS determination, as described in Methods, was assessed to determine if exposure of E. cloacae to $\mathrm{HAuCl}_{4}$ or $\mathrm{K}_{2} \mathrm{TeO}_{3}$ results in increased intracellular ROS (Figures 2A,B). While at short times exposure to $\mathrm{HAuCl}_{4}$ exhibited higher ROS content in anaerobiosis, after $15 \mathrm{~min}$ and $24 \mathrm{~h}$ the highest ROS content was observed in aerobic conditions (Figure 2A). Regarding tellurite exposure, significant differences in ROS content were observed only after $24 \mathrm{~h}$ (Figure 2B). In addition and irrespective of the presence of oxygen, ascorbic acid treatment decreased ROS production both in $\mathrm{HAuCl}_{4}$ - or $\mathrm{K}_{2} \mathrm{TeO}_{3}$-exposed cultures (Supplementary Figure S2).

It was also determined if exposure to the toxicants affects intracellular RSH concentration (Supplementary Table S2, Figures 2C,D). Upon $\mathrm{HAuCl}_{4}$ exposure, a soft trend to $\mathrm{RSH}$ decrease was observed in anaerobiosis (Figure 2C). In the case of $\mathrm{K}_{2} \mathrm{TeO}_{3}, \mathrm{RSH}$ were almost undetectable in the absence of oxygen after 15 min of exposure (Figure 2D).

Finally, and to assess how much of the toxicant was entering the cell, intracellular $\mathrm{HAuCl}_{4}$ and $\mathrm{K}_{2} \mathrm{TeO}_{3}$ were determined by ICP-OES as total Au and Te, respectively. Figure 3 shows that almost all the metal(loid) remains in the extracellular fraction.

\section{Gold and Tellurite Reduction by E. cloacae MF01 Cell Extracts}

The ability of crude extracts from E. cloacae MF01 to reduce $\mathrm{HAuCl}_{4}$ and $\mathrm{K}_{2} \mathrm{TeO}_{3}$ was analyzed under aerobic and anaerobic growth conditions, different $\mathrm{pH}$ values and electron donors (Figure 4). The extract showed the highest gold-reducing activity at $\mathrm{pH} 8.0$ using $\mathrm{NADH}$ as cofactor (Figure 4A). However, this activity was measurable at most $\mathrm{pH}$ values, irrespective of the electron donor used (Figures 4A,B); the exception was $\mathrm{pH}$ 7.0/NADH and $\mathrm{pH} 6.0 / \mathrm{NADPH}$. On the other hand, the extract showed tellurite reductase (TR) activity at all $\mathrm{pH}$ values, cofactors and the presence or absence of oxygen (Figures 4C,D). With $\mathrm{NADH}$ as cofactor, TR showed no variations among aerobic and anaerobic conditions at all $\mathrm{pH}$ values tested (Figure 4C). The highest TR activity was observed at $\mathrm{pH} 9.0$ using $\mathrm{NADH}$ as electron donor. In general, TR was higher in aerobic conditions at any $\mathrm{pH}$ tested, using NADPH as cofactor (Figure 4D).

\section{A}

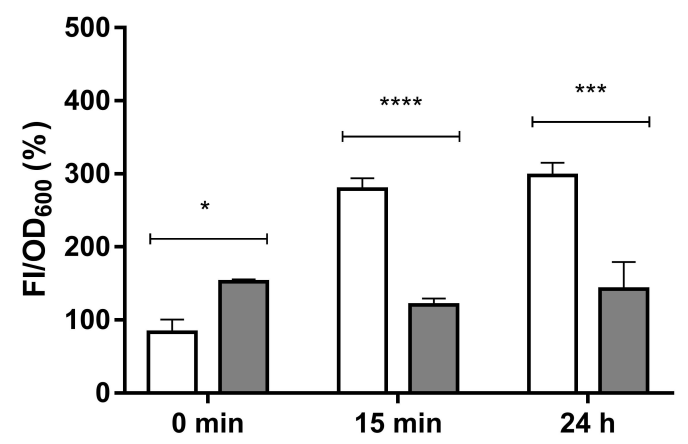

C

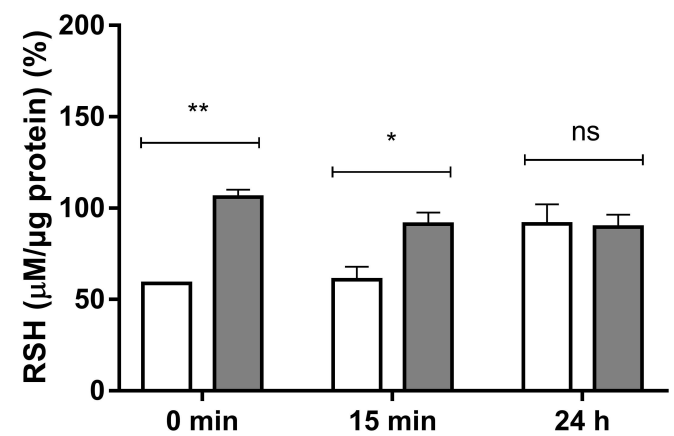

B

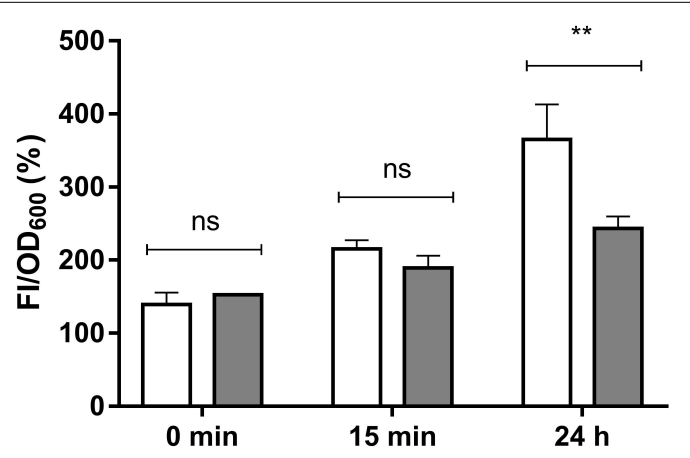

D

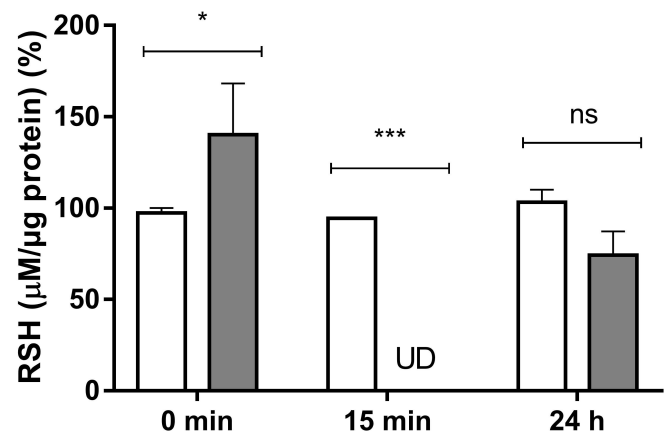

FIGURE 2 | Total ROS (A,B) and intracellular RSH (C,D) concentration in E. cloacae MF01 exposed to $\mathrm{HAuCl}_{4}$ or $\mathrm{K}_{2} \mathrm{TeO}_{3}$. Cells were treated for the indicated times with $\mathrm{HAuCl}_{4}(\mathbf{A}-\mathbf{C})$ or $\mathrm{K}_{2} \mathrm{TeO}_{3} \mathbf{( B , D )}$, in aerobic (white bars) or anaerobic conditions (gray bars). While $\mathrm{HAuCl}_{4}$ exposure concentrations were $0.25 \mathrm{mM}$ (aerobic) and $0.125 \mathrm{mM}$ (anaerobic), those of $\mathrm{K}_{2} \mathrm{TeO}_{3}$ were 0.008 and $0.016 \mathrm{mM}$, respectively. Fluorescence intensity and RSH concentrations were expressed as per cent of those values observed in the respective control conditions (100\%). The data represent the average of three independent tests \pm SD. ${ }^{*} p<0.0216$; ${ }^{* *} p<0.0012$; ${ }^{* * *} p<0.0002 ; * * * p<0.0001 ;$ ns, not significant; UD, undetectable. 

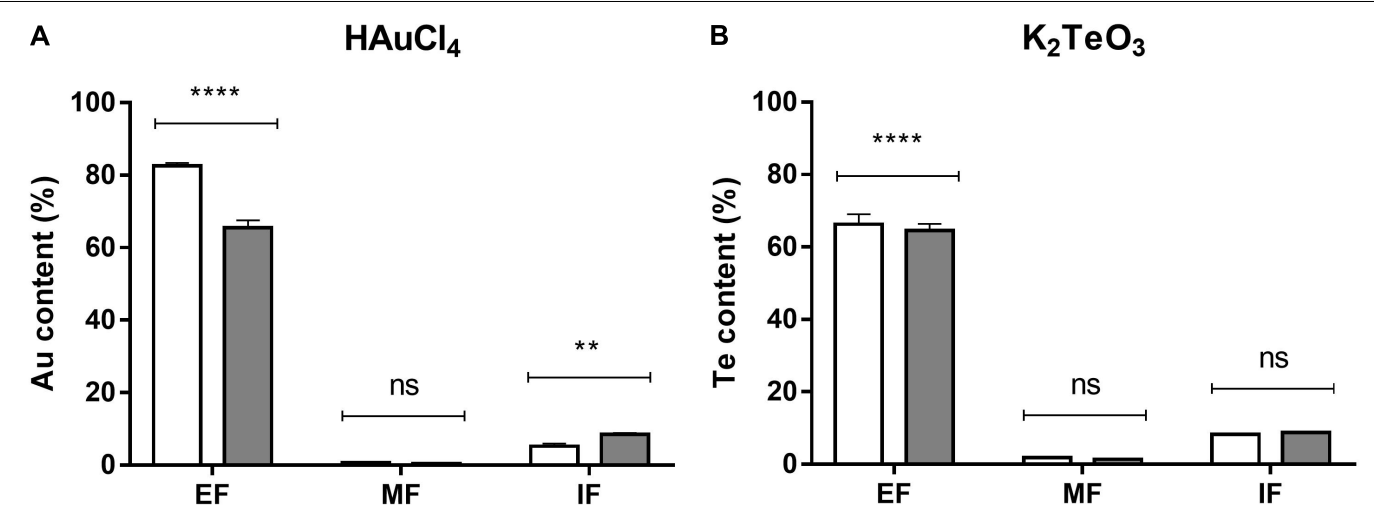

FIGURE 3 | Au and Te content in E. cloacae MF01 exposed to the indicated toxicants under aerobic and anaerobic growth conditions. Au and Te content was determined in the extracellular (EF), membrane (MF) and intracellular fractions (IF) of bacteria exposed to $\mathrm{HAuCl}_{4}(\mathbf{A})$ or $\mathrm{K}_{2} \mathrm{TeO}_{3}$ (B) for 15 min in aerobic (white bars) or anaerobic (gray bars) conditions. Toxic concentrations were as indicated in the legend to Figure $\mathbf{2}$. Au and Te content are expressed as \% of the initial treatment concentration. Bars represent the average of three independent tests $\pm \mathrm{SD}$. ${ }^{* *} p<0.0029$; ${ }^{* * * *} p<0.0001$; ns, not significant.

As reveled by SEM, E. cloacae MF01 produced EPSs when grown in the presence of $0.008 \mathrm{mM} \mathrm{K}_{2} \mathrm{TeO}_{3}$ (Supplementary Figures S3C,D) but not in the untreated control condition (Supplementary Figures S3A,B). This observation prompted us to analyze EPS-mediated $\mathrm{HAuCl}_{4}$ - and $\mathrm{K}_{2} \mathrm{TeO}_{3}$-reducing activities in aerobic and anaerobic growth conditions (Figure 4). EPS exhibited only gold-reducing activity, which was always higher in aerobic conditions both at $\mathrm{pH} 6.0$ and 7.0. Interestingly, the highest activity was observed at pH 6.0 with untreated EPS or after nuclease digestion (benzonase, Figure 4E). Protease (subtilisin BPN') treatment decreased gold-reducing activity at pH 6.0 and 7.0 (Figures 4E,F).

The chemical composition of purified EPS from E. cloacae MF01 was examined and the results showed that EPS contained a higher protein concentration when purified from anaerobicallygrown cells $(0.28 \pm 0.13$ vs. $0.24 \pm 0.13)$.

\section{Synthesis and Characterization of NS Synthesized Using E. cloacae MF01 Cell Extracts}

In general, in vitro nanostructure synthesis by crude extracts of this bacterium lasted about $16 \mathrm{~h}$. NS were generated at different $\mathrm{pH}$ values, electron donors and in the presence or absence of oxygen. Gold-containing nanostructures (AuNS) were synthesized in the following conditions: (i) $\mathrm{O}_{2}+\mathrm{NADH}+$ $\mathrm{pH}$ 9.0, (ii) $\mathrm{O}_{2}+\mathrm{NADPH}+\mathrm{pH}$ 8.0, and (iii) $\mathrm{O}_{2}+\mathrm{NADPH}$ $+\mathrm{pH}$ 9.0, (iv) $-\mathrm{O}_{2}+\mathrm{NADH}+\mathrm{pH}$ 8.0, (v) $-\mathrm{O}_{2}+\mathrm{NADH}$ $+\mathrm{pH}$ 9.0, and (vi) $-\mathrm{O}_{2}+\mathrm{NADPH}+\mathrm{pH}$ 9.0. In turn, tellurium-containing nanostructures (TeNS) were synthesized aerobically and anaerobically in the following conditions: (i) $\mathrm{NADH}+\mathrm{pH}$ 8.0, (ii) $\mathrm{NADH}+\mathrm{pH}$ 9.0, (iii) $\mathrm{NADPH}+\mathrm{pH}$ 8.0, and (iv) NADPH $+\mathrm{pH}$ 9.0. Supplementary Table S3 shows NS concentrations. The highest production of AuNS was accomplished under anaerobic conditions; those synthesized at $\mathrm{pH} 8.0 / \mathrm{NADH}$ exhibited a concentration of $1,600 \mu \mathrm{g} / \mathrm{mL}$, while the highest production of these NS was at $\mathrm{pH} 9 / \mathrm{NADH}$ with a concentration of $900 \mu \mathrm{g} / \mathrm{mL}$. Best conditions for TeNS production were aerobiosis, $\mathrm{pH} 9.0 / \mathrm{NADPH}(700 \mu \mathrm{g} / \mathrm{mL})$.

Nanostructure and chemical composition of AuNS and TeNS were determined by transmission electron microscopy (TEM) and energy-dispersive X-ray spectroscopy (EDS), respectively. Figures 5, 6 shows AuNS synthesized under aerobic and anaerobic conditions, respectively. NS exhibited a heterogeneous morphology, including some degree of aggregation, thus forming structures of larger size. TEM showed some more electron-dense material, chiefly in the aggregated material. With the exception of those structures shown in Figure 5 (bottom panel) and 6 (upper panel), in general AuNS size was < $50 \mathrm{~nm}$. Aerobically synthesized NS showed a gold content of 6.6, 15.4, and 16.5\% (Figures 5A-C, respectively), and contained high amounts of carbon and oxygen. Excepting the NS shown in Figure 6C, anaerobically synthesized nanostructures contained less gold than their aerobic counterparts.

Finally and independently of the presence of oxygen, TeNS exhibited a uniform, nanostick-like morphology of $\sim 50 \mathrm{~nm}$. As with AuNS, in some cases aggregates of $\sim 200 \mathrm{~nm}$ were observed (Figures 7C, 8D). Tellurium content of aerobic NS was $18.9,24.4,13.5$, and $1.7 \%$ (Figures $7 \mathrm{~A}-\mathrm{D}$, respectively). In turn, anaerobically-generated TeNS exhibited a tellurium content of 15.8, 22.5, 5.1, and 21.1\% (Figures 8A-D, respectively).

\section{DISCUSSION}

Environmental bacteria thrive in places where growth conditions are very variable, often hostile, such as high or low temperatures, nutrient deprivation, and presence of toxic agents, among others (Bollag et al., 1994). In general, microorganism survival in the presence of toxic agents such as metals and/or metalloids is supported by specific mechanisms that allow them tolerating these agents (Summers and Silver, 1978). Among them, toxicant reduction has caught the attention of researchers, who are using natural or genetically modified metal(loid)reducing bacteria in the field of bioremediation to decontaminate 


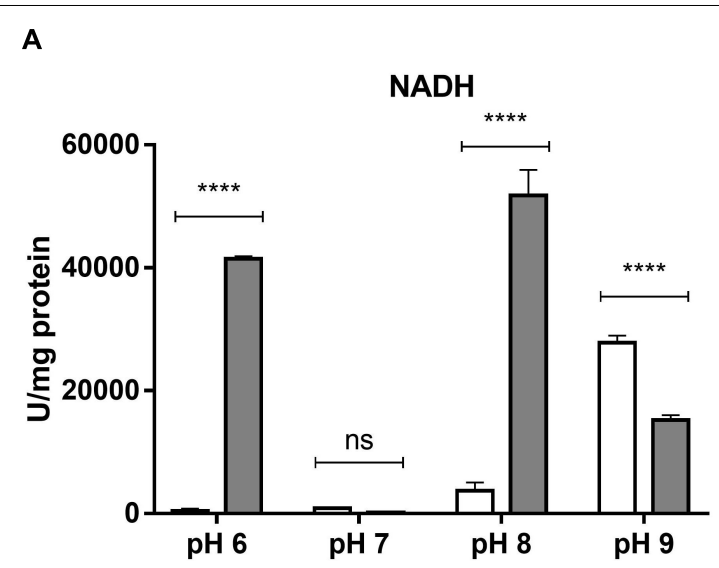

C

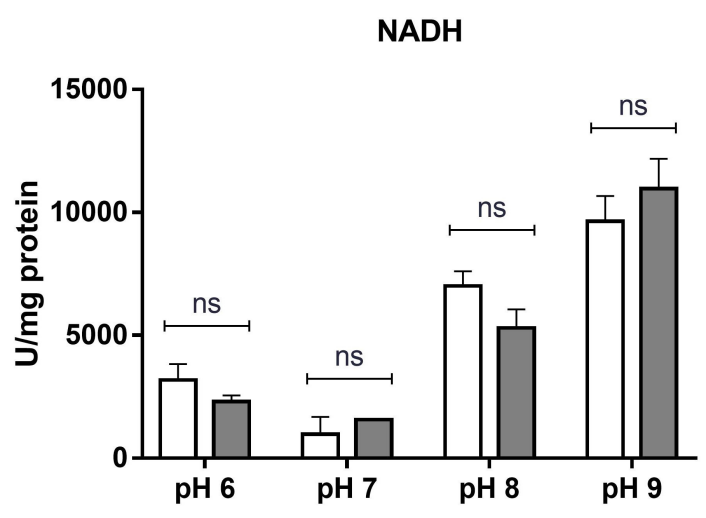

E

pH 6

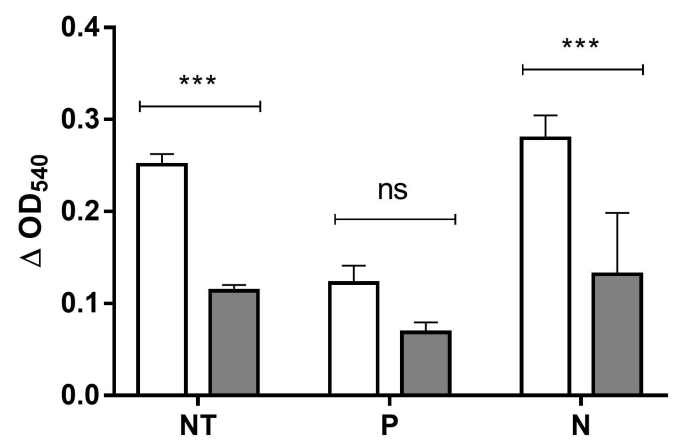

B

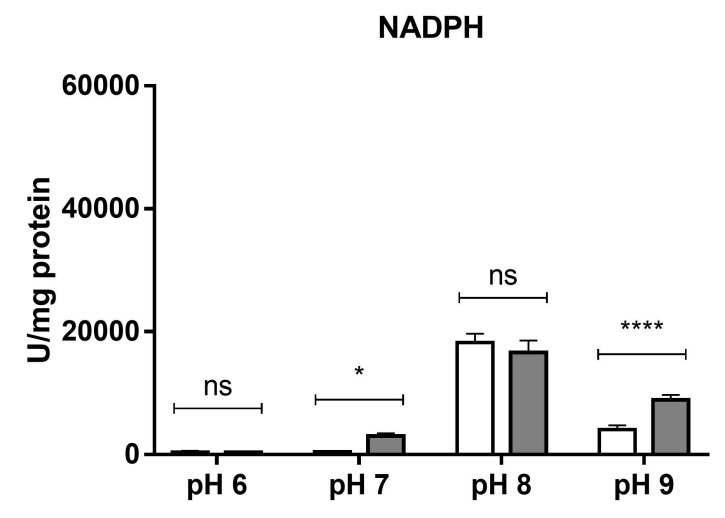

D

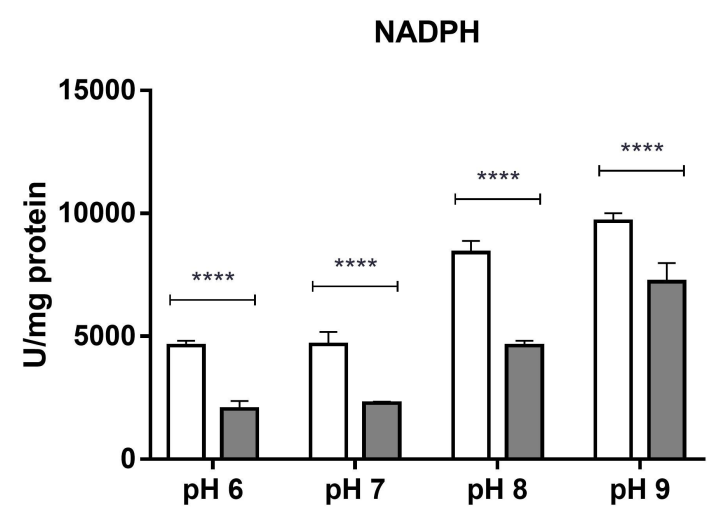

F

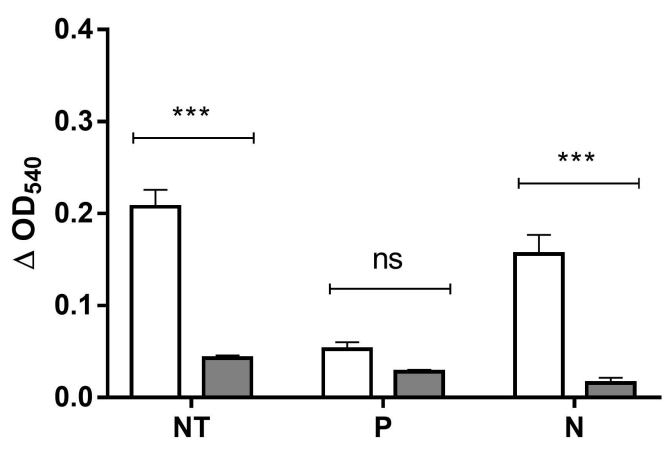

FIGURE $4 \mid \mathrm{HAuCl}_{4}$ and $\mathrm{K}_{2} \mathrm{TeO}_{3}$ reducing activity by crude extracts or EPS from E. cloacae MFO1. $\mathrm{HAuCl}_{4} \mathbf{( A , B )}$ - or $\mathrm{K}_{2} \mathrm{TeO}_{3}$ (C,D)-reducing activity by crude extracts of $E$. cloacae MF01 was assessed either with NADH or NADPH, at pH values 6.0, 7.0, 8.0 and 9.0, under aerobic (white bars) and anaerobic conditions (gray bars). Assays for $\mathrm{HAuCl}_{4}$-reducing activity mediated by EPS (E,F) were carried out using samples without treatment (NT) and with previous protease (P) or nuclease $(\mathrm{N})$ treatments, at the indicated $\mathrm{pH}$ values and under aerobic (white bars) or anaerobic conditions (gray bars). Bars represent the average of three independent tests \pm SD. ${ }^{*} p<0.05 ;{ }^{* *} p<0.0002 ;{ }^{* * * *} p<0.0001$; ns, no significant.

polluted sites (Stephen and Macnaughton, 1999; Das et al., 2016). In addition, these bacteria are also being employed in biotechnology, since microorganism-mediated metal(loid) reduction often ends in the generation of nanoscaled structures that may exhibit biomedical, electronic, and pharmacological applications (Suresh, 2012).
Although E. cloacae MF01 is highly resistant to $\mathrm{HAuCl}_{4}$ under aerobic growth conditions, toxicity tests showed that precisely in this condition it contains enhanced ROS levels as well as a decreased RSH concentration. ROS resistance may be related to the antioxidant defense system of this bacterium, i.e., catalase, peroxidase, and superoxide dismutase which eliminate toxic 

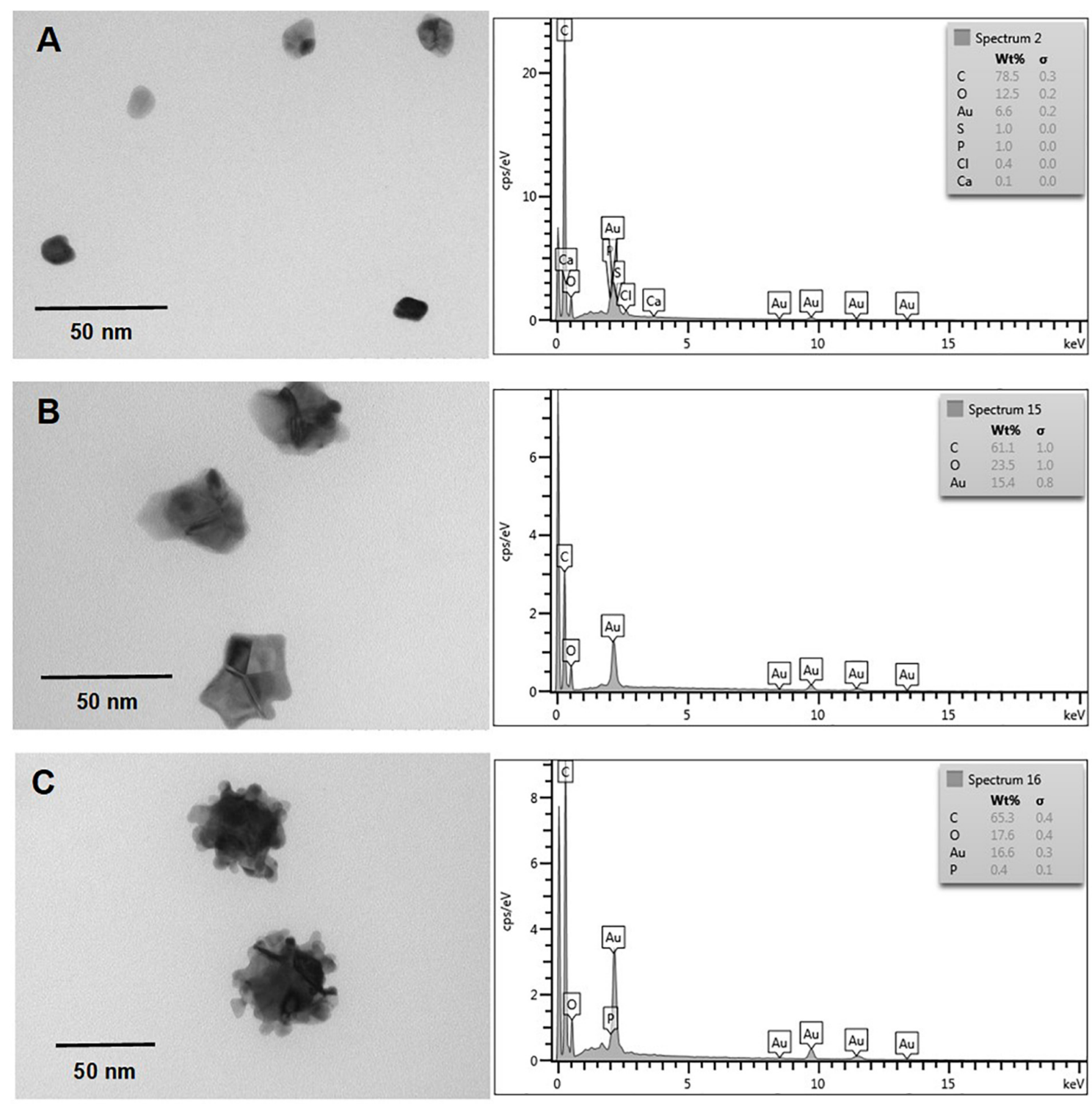

FIGURE 5 | In vitro, aerobic synthesis of AuNS by E. cloacae MF01 crude extracts. Electron micrographs (left) and EDS analysis (right) show AuNS synthesized under the following experimental conditions: (A) NADH/pH 9.0; (B) NADPH/pH 8.0; (C) NADPH/pH 9.0.

forms of oxygen would protect cell components that are prone to damage such as proteins, cell membranes, and the genetic material (Imlay et al., 1988; Touati et al., 1995; Stadtman and Levine, 2000; Imlay, 2003; Helbig et al., 2008; Hong et al., 2012; Lemire et al., 2013). In this line, while it has been observed that ROS generation is not necessarily related to metal toxicity in E. coli (Vrionis et al., 2015), gold exposure results in decreased RSH levels (Shaw, 1999).

Enterobacter cloacae MF01 showed higher tellurite resistance in anaerobiosis, where toxicity tests indicated that there was no decrease in RSH concentration or increased ROS generation. It is well-known that one of cell tellurite targets are reduced thiols, which decrease drastically after toxicant exposure (Turner et al., 1999). As RSH are not affected in a ROS-free environment, tellurite toxicity should be lower in anaerobic growth conditions.

After $15 \mathrm{~min}$ exposure to $\mathrm{HAuCl}_{4}$ or $\mathrm{K}_{2} \mathrm{TeO}_{3}$, most part $(90 \%)$ of the metal(loid) remains in the extracellular fraction. While tellurite entrance is mediated mainly by the phosphate transporter PitA and/or by the acetate transporter ActP (Borghese et al., 2011; Elías et al., 2012, 2015), that of gold would be mediated by sulfhydryl group-rich membrane proteins (Snyder et al., 1986). As mentioned, about $10 \%$ of the toxicants enter the cell, which could generate an adaptive response thus enabling it to better respond to toxicant-mediated damage in aerobic (gold) or anaerobic growth conditions (tellurite).

Intracellular $\mathrm{HAuCl}_{4}$ - or $\mathrm{K}_{2} \mathrm{TeO}_{3}$-reducing activity from aerobic and anaerobic cultures was analyzed in the $\mathrm{pH}$ range 

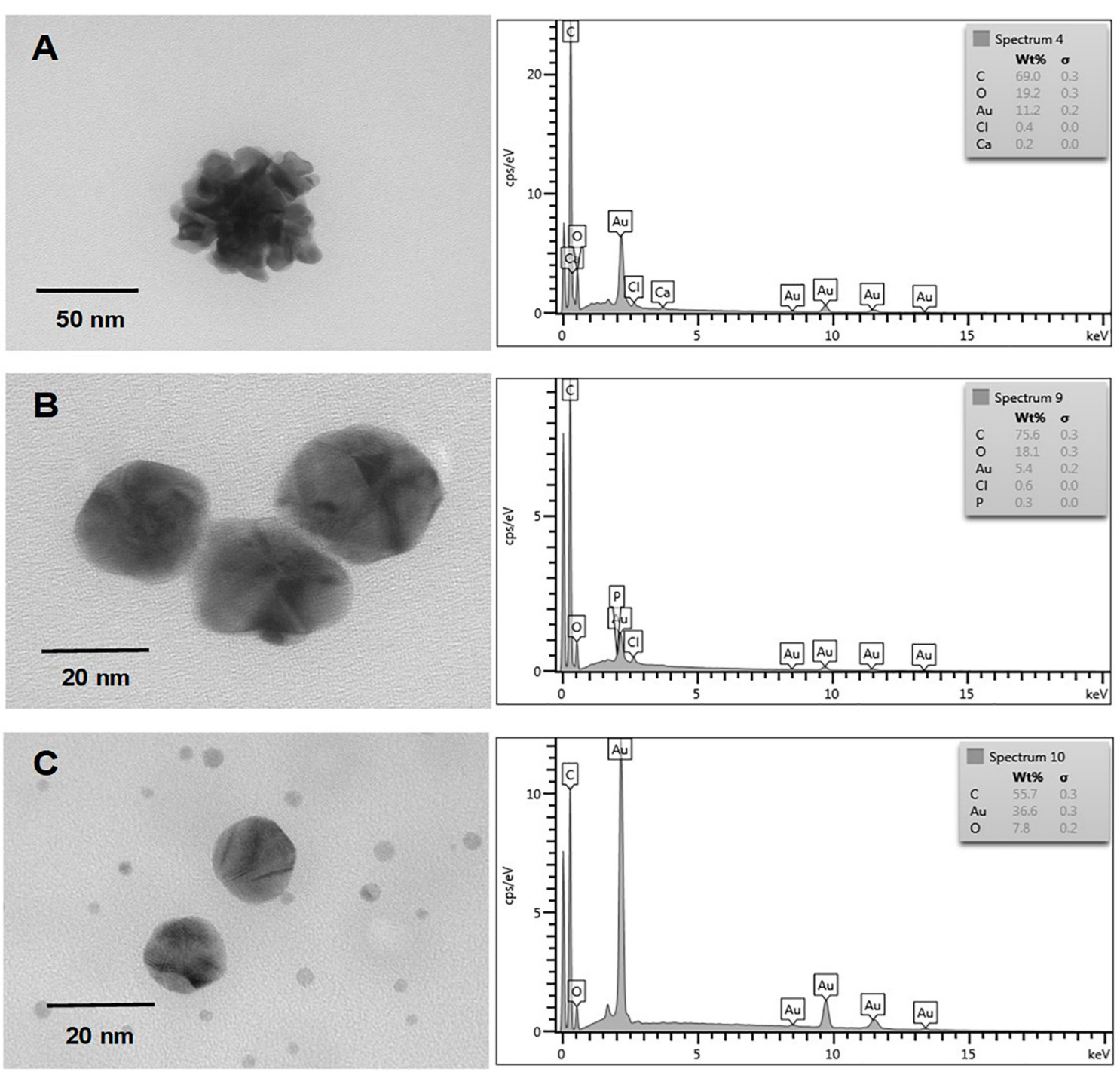

FIGURE 6 | In vitro, anaerobic synthesis of AuNS by E. cloacae MF01 crude extracts. Electron micrographs (left) and EDS analysis (right) show AuNS synthesized under the following experimental conditions: (A) NADH/pH 8.0; (B) NADH/pH 9.0; (C) NADPH/pH 9.0.

6.0-9.0, using NADH or NADPH as electron donor. Gold and tellurite reductase activities were observed at all $\mathrm{pH}$ values assayed irrespective of the electron donor used. Probably $\mathrm{pH}$ is responsible for metal speciation, which results in complex formation and/or protonation/deprotonation of amino acids groups that may participate in protein stabilization (Panda and Deepa, 2011). That is the case of proteins exhibiting tellurite reductase activity, whose redox centers contain catalytically important cysteine residues that are sensitive to $\mathrm{pH}$ (Arenas et al., 2014). Thiol group deprotonation of vicinal cysteine residues gives rise to the thiolate anion, which is highly reactive exhibiting a pKa 8.0 (Vlamis-Gardikas, 2008). Metal(oid)reducing activity was evaluated only at $37^{\circ} \mathrm{C}$, the optimal growth temperature for E. cloacae MF01 (Arenas-Salinas et al., 2016), so further optimization of the reducing activity could result from assaying it at different temperatures.
The enzymatic reduction of tellurite generates concomitantly superoxide as a by product, which increases intracellular ROS levels causing oxidative stress and cell damage (Chasteen et al., 2009). In this line, this bacterium exhibits an efficient adaptive response to oxidative stress in aerobic conditions, thus helping enzymes responsible for toxicant reduction to be unaffected (Imlay, 2003). Under anaerobic growth conditions toxicant treatment does not ends in ROS formation, thus reducing protein damage and, therefore, reducing activity (Ercal et al., 2001).

Little is known regarding enzymatic gold reduction. One report states that glutathione reductase from $E$. coli catalyzes $\mathrm{HAuCl}_{4}$ reduction in a NADPH-dependent manner (Scott et al., 2008). This contrasts with tellurite reduction, where various bacterial enzymes have been shown to possess the ability to reduce tellurite. These include (i) nitrate reductases (Avazéri et al., 1997), (ii) terminal oxidases of the electron 

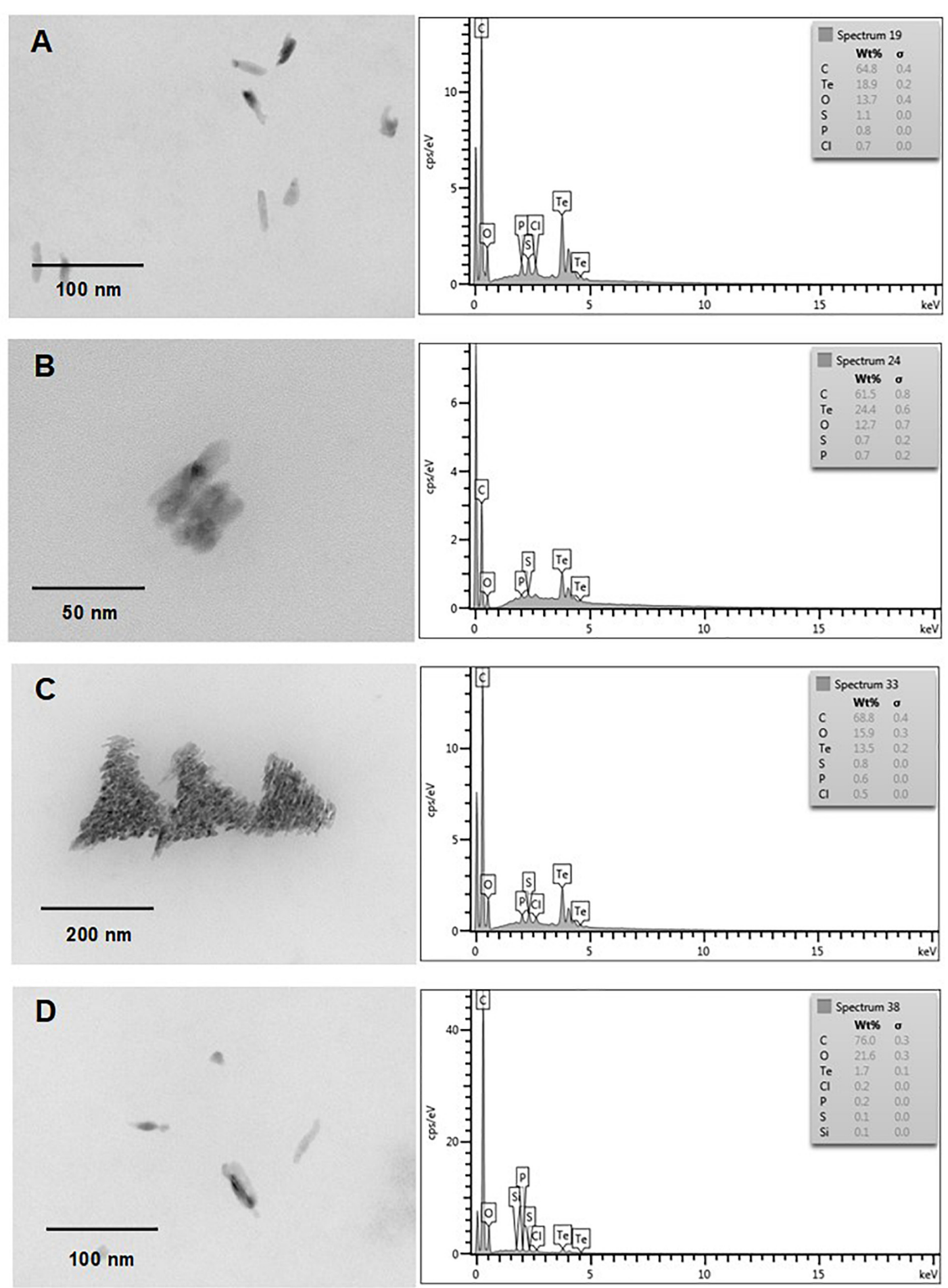

FIGURE 7 | In vitro, aerobic synthesis of TeNS by E. cloacae MF01 crude extracts. Electron micrographs (left) and EDS analysis (right) show TeNS synthesized under the following experimental conditions: (A) NADH/pH 8.0; (B) NADPH/pH 8.0; (C) NADH/pH 9.0; (D) NADPH/pH 9.0.

transport chain of several Gram-negative bacteria (Trutko et al., 2000; Díaz-Vásquez et al., 2015), (iii) catalase (Calderón et al., 2006), (iv) isocitrate dehydrogenase and 6-phosphogluconate dehydrogenase from E. coli (Reinoso et al., 2012;
Sandoval et al., 2015), (v) glutathione reductase from Pseudomonas sp. BNF22 (Pugin et al., 2014), (vi) dihydrolipoamide dehydrogenase (Castro et al., 2008; Arenas et al., 2014), thioredoxin reductase and alkyl hydroperoxide 

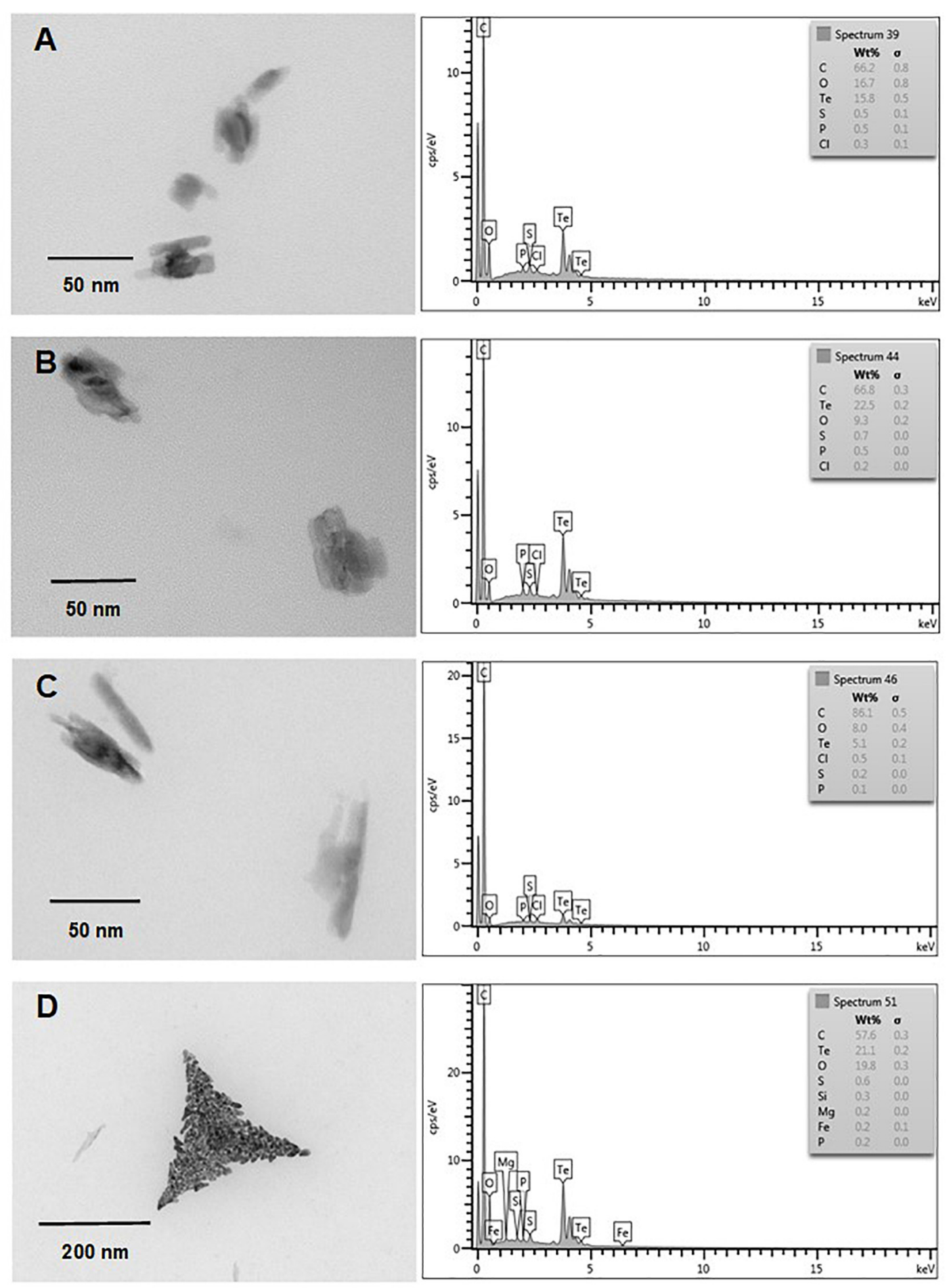

FIGURE 8 | In vitro, anaerobic synthesis of TeNS by E. cloacae MF01 crude extracts. Electron micrographs (left) and EDS analysis (right) show TeNS synthesized under the following experimental conditions: (A) NADH/pH 8.0; (B) NADPH/pH 8.0; (C) NADH/pH 9.0; (D) NADPH/pH 9.0.

reductase from S. haemolyticus BNF01, vii) glutathione reductase, flavorubredoxin reductase, dihydrolipoamide dehydrogenase and a putative oxidoreductase from E. coli (Arenas-Salinas et al., 2016). In addition, it was recently communicated that glutathione reductase from E. cloacae MF01 exhibits tellurite reductase activity (Figueroa et al., 2018).

On the other hand, putative extracellular EPS-mediated $\mathrm{HAuCl}_{4}$ - and $\mathrm{K}_{2} \mathrm{TeO}_{3}$-reducing activities were also evaluated in 
the $\mathrm{pH}$ range 6.0-9.0. To determine if any protein and/or nucleic acid contributed to the observed activity, EPS preparations were treated with proteases or nucleases prior the reducing assay. A similar mechanism has been described in E. cloacae SUKCr1D, where the EPS from this microorganism can reduce $\mathrm{Cr}(\mathrm{VI})$ to Cr(III) (Harish et al., 2012).

Extracellular polymeric substance dependent gold-reducing activity was observed only at $\mathrm{pH} 6.0$ and 7.0 , in contrast to the results obtained with crude extracts, which revealed gold-reducing activity mainly at $\mathrm{pH} 8.0$ and 9.0. An obvious explanation is that extracellular gold reduction is being carried out by different agents from those forming part of the EPS (Wingender et al., 1999). Since EPS composition is highly variable and depends on the bacterial species and culture conditions, it is very hard to determine the true catalyst(s) (van Hullebusch et al., 2003). In this context, Guibaud et al. (2005) described that purified EPS from E. cloacae SUKCr1D is mainly composed of polysaccharides (22 $\mathrm{mg} / \mathrm{g})$, proteins $(130 \mathrm{mg} / \mathrm{g})$, nucleic(28 mg/g), and uronic acids (56 mg/g). Our results of EPSmediated gold-reducing activity support the importance of proteins in the process, since EPS treatment with proteases decreased gold-reducing activity almost to half of that exhibited by untreated EPS irrespective of the presence of oxygen.

Conversely to that observed for $\mathrm{HAuCl}_{4}$, no EPS-mediated tellurite reductase activity was found under the tested conditions. Despite this, a white precipitate was always formed. Probably tellurite interacts with positively charged groups that are present in EPS components (i.e., $\mathrm{NH}_{3}{ }^{+}$present in amino sugars and proteins), which could chelate the toxicant (Pal and Paul, 2008). A similar result was observed with E. cloacae strain P2B EPS, where carboxyl and hydroxyl groups interact with and sequester $\mathrm{Pb}^{2+}$ (Naik et al., 2012).

Enterobacter cloacae MF01 crude extracts were used to generate metal(loid)-containing NS at the same conditions of $\mathrm{pH}$, enzyme cofactor, and growth conditions that were utilized in metal(loid)-reducing activity tests. In general, reducing activity and NS generation correlated well, excepting for $\mathrm{HAuCl}_{4}$ reducing activity from anaerobic cultures at $\mathrm{pH} 6.0$ in the presence of NADH.

AuNS as well as TeNS showed a size $<50 \mathrm{~nm}$, i.e., within the classification of nanostructures (Laurent et al., 2010). While AuNS exhibited circular morphology with irregular borders, TeNS showed a stick-like morphology, commonly referred to as nanosticks. NS size and morphology are parameters of great importance because they control some of the properties the NS exhibit. In fact, the unique physical and chemical properties of NS are dependent on their size, while reactivity, resistance, and other properties are controlled through their size, shape, and structure (Khan et al., 2017). In fact, NS size and morphology is determined during the process of NS formation itself with two crucial stages controlling these parameters: nucleation (the process by which two or more atoms collide to form a cluster) and particle growth (starting when the smallest cluster size reaches the stability at the particular synthesis conditions) (Xiong and $\mathrm{Lu}, 2015)$. TeNS synthesized at $\mathrm{pH} 9.0 / \mathrm{NADH} /+\mathrm{O}_{2}$ and $\mathrm{pH}$ 9.0/NADPH/ $-\mathrm{O}_{2}$ showed different morphology and smaller size than their counterparts synthesized under the other conditions tested. TeNS appeared as aggregates, which is probably due to size reduction and increased attractive forces that allow NS to interact with each other (Khan et al., 2017). In turn, AuNS exhibited a range of characteristic colors and properties (Dreaden et al., 2012).

Finally and as expected, the chemical composition determined by EDS showed that $\mathrm{Au}$ and Te content within NS vary with specific conditions of synthesis. Particularly, one would have anticipated that NS synthesized in anaerobic conditions displayed higher metal(loid) content since metal(loid) oxidation is avoided thus facilitating NS formation (Zare et al., 2013).

\section{CONCLUSION}

The environmental isolate E. cloacae MF01 showed higher resistance to $\mathrm{HAuCl}_{4}$ and $\mathrm{K}_{2} \mathrm{TeO}_{3}$ under aerobic and anaerobic growth conditions, respectively. Toxicant's toxicity was due to ROS generation and RSH depletion. E. cloacae MF01 displayed intra- and extra-cellular $\mathrm{HAuCl}_{4}$ reduction and only intracellular $\mathrm{K}_{2} \mathrm{TeO}_{3}$-reducing activity. Since in most cases the highest reducing activity did not correlate with higher toxicant resistance, it could be inferred that another resistance mechanism, still unknown, may be involved in alleviating the effects of these toxicants. Finally, the biological synthesis of $\mathrm{Au}$ - and $\mathrm{Te}$ - containing NS by crude extracts from E. cloacae MF01 could represent a start point to support future interesting biotechnological applications.

\section{AUTHOR CONTRIBUTIONS}

FC, CM-V, CV, and FA conceived and designed the experiments and analyzed the data. FC, EV, KJ, MF, and CM-V performed the experiments. $\mathrm{CV}$ and FA contributed reagents, materials, analysis tools, and wrote the paper.

\section{FUNDING}

This work received financial support from FONDECYT (Fondo Nacional de Ciencia y Tecnología) Iniciación en la Investigación \#11140334 (FA), Regular \#1160051 (CV), and Basal FB0807 $(\mathrm{EV})$, Support from DICYT (Dirección de Investigación en Ciencia y Tecnología, Universidad de Santiago de Chile) is also acknowledged.

\section{ACKNOWLEDGMENTS}

The authors thank Dr. Fabian Cornejo from the Universidad de Santiago de Chile, Facultad de Química y Biología, for his constant support in carrying out the experiments.

\section{SUPPLEMENTARY MATERIAL}

The Supplementary Material for this article can be found online at: https://www.frontiersin.org/articles/10.3389/fmicb.2018. 03118/full\#supplementary-material 


\section{REFERENCES}

Albalasmeh, A. A., Berhe, A. A., and Ghezzehei, T. A. (2013). A new method for rapid determination of carbohydrate and total carbon concentrations using UV spectrophotometry. Carbohydr. Polym. 97, 253-261. doi: 10.1016/j.carbpol. 2013.04.072

Amstad, E., Textor, M., and Reimhult, E. (2011). Stabilization and functionalization of iron oxide nanoparticles for biomedical applications. Nanoscale 3, 28192843. doi: 10.1039/clnr10173k

Arenas, F. A., Leal, C. A., Pinto, C. A., Arenas-Salinas, M. A., Morales, W. A., Cornejo, F. A., et al. (2014). On the mechanism underlying tellurite reduction by Aeromonas caviae ST dihydrolipoamide dehydrogenase. Biochimie 102, 174-182. doi: 10.1016/j.biochi.2014.03.008

Arenas-Salinas, M., Vargas, J. I., Morales, W., Pinto, C., Muñoz, P., Cornejo, F. A., et al. (2016). Flavoprotein-mediated tellurite reduction: structural basis and applications to the synthesis of tellurium-containing nanostructures. Front. Microbiol. 7:1160. doi: 10.3389/fmicb.2016.01160

Avazéri, C., Turner, R. J., Pommier, J., Weiner, J. H., Giordano, G., and Verméglio, A. (1997). Tellurite reductase activity of nitrate reductase is responsible for the basal resistance of Escherichia coli to tellurite. Microbiology 143, 181-189. doi: 10.1099/00221287-143-4-1181

Azam, A., Ahmed, A. S., Oves, M., Khan, M. S., Habib, S. S., and Memic, A. (2012). Antimicrobial activity of metal oxide nanoparticles against gram-positive and gram-negative bacteria: a comparative study. Int. J. Nanomed. 7, 6003-6009. doi: $10.2147 /$ IJN.S35347

Bao, H., Lu, Z., Cui, X., Qiao, Y., Guo, J., Anderson, J. M., et al. (2010). Extracellular microbial synthesis of biocompatible CdTe quantum dots. Acta Biomater. 6, 3534-3541. doi: 10.1016/j.actbio.2010.03.030

Bollag, J. M., Mertz, T., and Otjen, L. (1994). "Role of microorganisms in soil bioremediation," in Bioremediation Through Rhizosphere Technology, eds T. Anderson and J. Coats (Washington, DC: American Chemical Society), 2-10. doi: 10.1021/bk-1994-0563.ch001

Borghese, R., Cicerano, S., and Zannoni, D. (2011). Fructose increases the resistance of Rhodobacter capsulatus to the toxic oxyanion tellurite through repression of acetate permease (ActP). Antonie Van Leeuwenhoek 100, 655-658. doi: 10.1007/s10482-011-9619-5

Bradford, M. M. (1976). A rapid and sensitive method for the quantitation of microgram quantities of protein utilizing the principle of protein-dye binding. Anal. Biochem. 72, 248-254. doi: 10.1016/0003-2697(76)90527-3

Bramhachari, P. V., and Dubey, S. K. (2006). Isolation and characterization of exopolysaccharide produced by Vibrio harveyi strain VB23. Lett. Appl. Microbiol. 43, 571-577. doi: 10.1111/j.1472-765X.2006.01967.x

Calderón, I. L., Arenas, F. A., Pérez, J. M., Fuentes, D. E., Araya, M. A., Saavedra, C. P., et al. (2006). Catalases are NAD(P)H-dependent tellurite reductases. PLoS One 1:e70. doi: 10.1371/journal.pone.0000070

Castro, M., Molina, R., Díaz, W., Pichuantes, S., and Vásquez, C. (2008). The dihydrolipoamide dehydrogenase of Aeromonas caviae ST exhibits NADHdependent tellurite reductase activity. Biochem. Biophys. Res. Commun. 375, 91-94. doi: 10.1016/j.bbrc.2008.07.119

Chasteen, T. G., Fuentes, D. E., Tantaleán, J. C., and Vásquez, C. C. (2009). Tellurite: history, oxidative stress, and molecular mechanisms of resistance. FEMS Microbiol. Rev. 33, 1-13. doi: 10.1111/j.1574-6976.2009.00177.x

Cioffi, N., and Rai, M. (eds) (2012). Nano-Antimicrobials: Progress and Prospects. Berlin: Springer Science. doi: 10.1007/978-3-642-24428-5

Correa-Llantén, D., Muñoz-Ibacache, S., Castro, M., Muñoz, P., and Blamey, J. (2013). Gold nanoparticles synthesized by Geobacillus sp. strain ID17 a thermophilic bacterium isolated from deception Island, Antarctica. Microb. Cell Fact. 12:75. doi: 10.1186/1475-2859-12-75

Cui, Y., Zhao, Y., Tian, Y., Zhang, W., Lu, X., and Jiang, X. (2012). The molecular mechanism of action of bacterial gold nanoparticles on E. coli. Biomaterials 33, 2327-2333. doi: 10.1016/j.biomaterials.2011.11.057

Das, S., Dash, H., and Chakraborty, J. (2016). Genetic basis and importance of metal resistant genes in bacteria for bioremediation of contaminated environments with toxic metal pollutants. Appl. Microbiol. Biotechnol. 100, 2967-2984. doi: 10.1007/s00253-016-7364-4

Díaz-Vásquez, W., Abarca-Lagunas, M., Cornejo, F., Pinto, C., Arenas, F., and Vásquez, C. (2015). Tellurite-mediated damage to the Escherichia coli
NDH-dehydrogenases and terminal oxidases in aerobic conditions. Arch. Biochem. Biophys. 566, 67-75. doi: 10.1016/j.abb.2014.10.011

Dimkpa, C. O., Svatos, A., Dabrowska, P., Schmidt, A., Boland, W., and Kothe, E. (2008). Involvement of siderophore in the reduction of metal-induced inhibition of auxin synthesis in Streptomyces spp. Chemosphere 74, 19-25. doi: 10.1016/j.chemosphere.2008.09.079

Dohnalkova, A., Marshall, M. J., Kennedy, D. W., Gorby, Y. A., Shi, L., Beliaev, A., et al. (2005). The role of bacterial exopolymers in metal sorption and reduction. Microsc. Microanal. 11, 116-117. doi: 10.1017/S1431927605506688

Dreaden, E. C., Alkilany, A. M., Huang, X., Murphy, C. J., and El-Sayed, M. A. (2012). The golden age: gold nanoparticles for biomedicine. Chem. Soc. Rev. 41, 2740-2779. doi: 10.1039/C1CS15237H

Elías, A., Díaz-Vásquez, W., Abarca-Lagunas, M., Chasteen, T., Arenas, F., and Vásquez, C. (2015). The ActP acetate transporter acts prior to the PitA phosphate carrier in tellurite uptake by Escherichia coli. Microbiol. Res. 177, 15-21. doi: 10.1016/j.micres.2015.04.010

Elías, A. O., Abarca, M. J., Montes, R. A., Chasteen, T. G., Pérez-Donoso, J. M., and Vásquez, C. C. (2012). Tellurite enters Escherichia coli mainly through the PitA phosphate transporter. Microbiol. Open 1, 259-267. doi: 10.1002/mbo3.26

Ercal, N., Gurer-Orhan, H., and Aykin-Burns, N. (2001). Toxic metals and oxidative stress part I: mechanisms involved in metal-induced oxidative damage. Curr. Top. Med. Chem. 1, 529-539. doi: 10.2174/15680260133 94831

Figueroa, M., Fernández, V., Arenas-Salinas, M., Ahumada, D., MuñozVillagrán, C., Cornejo, F., et al. (2018). Synthesis and antibacterial activity of metal(loid) nanostructures by environmental multi-metal(loid) resistant bacteria and metal(loid)-reducing flavoproteins. Front. Microbiol. 9:959. doi: 10.3389/fmicb.2018.00959

Guibaud, G., Comte, S., Bordas, F., Dupuy, S., and Baudu, M. (2005). Comparison of the complexation potential of extracellular polymeric substances (EPS), extracted from activated sludges and produced by pure bacteria strains, for cadmium, lead and nickel. Chemosphere 59, 629-638. doi: 10.1016/j. chemosphere.2004.10.028

Harish, R., Samuel, J., Mishra, R., Chandrasekaran, N., and Mukherjee, A. (2012). Bio-reduction if $\mathrm{Cr}(\mathrm{VI})$ by exopolysaccharides (EPS) from indigenous bacterial species of Sukinda chromite mine. India Biodegradation 23, 487-496. doi: 10. 1007/s10532-011-9527-4

Harrison, J., Ceri, H., and Turner, R. J. (2007). Multimetal resistance and tolerance in microbial biofilms. Nat. Rev. Microbiol. 5, 928-938. doi: 10.1038/ nrmicro1774

Harrison, J. J., Ceri, H., Stremick, C. A., and Turner, R. J. (2004). Biofilm susceptibility to metal toxicity. Environ. Microbiol. 6, 1220-1227. doi: 10.1111/ j.1462-2920.2004.00656.x

Helbig, K., Grosse, C., and Nies, D. H. (2008). Cadmium toxicity in glutathione mutants of Escherichia coli. J. Bacteriol. 190, 5439-5454. doi: 10.1128/JB.0027208

Heuts, D., Scrutton, N., McIntire, W., and Fraaije, M. (2009). What's in a covalent bond? On the role and formation of covalently bound flavin cofactors. FEBS J. 276, 3405-3427. doi: 10.1111/j.1742-4658.2009.07053.x

Hong, R., Kang, T. Y., Michels, C. A., and Gadura, N. (2012). Membrane lipid peroxidation in copper alloy-mediated contact killing of Escherichia coli. Appl. Environ. Microbiol. 78, 1776-1784. doi: 10.1128/AEM.07068-11

Imlay, J. A. (2003). Pathways of oxidative damage. Annu. Rev. Microbiol. 57, 395-418. doi: 10.1146/annurev.micro.57.030502.090938

Imlay, J. A., Chin, S. M., and Linn, S. (1988). Toxic DNA damage by hydrogen peroxide through the fenton reaction in vivo and in vitro. Science 240, 640-642. doi: $10.1126 /$ science. 3287616

Khan, I., Saeed, K., and Khan, I. (2017). Nanoparticles: properties, applications and toxicities. Arab. J. Chem. (in press). doi: 10.1016/j.arabjc.2017.05.011

Laurent, S., Forge, D., Port, M., Roch, A., Robic, C., Vander Elst, L., et al. (2010). Magnetic iron oxide nanoparticles: synthesis, stabilization, vectorization, physicochemical characterizations, and biological applications. Chem. Rev. 108, 2064-2110. doi: 10.1021/cr900197g

Lemire, J., Mailloux, R., Auger, C., Whalen, D., and Appanna, V. (2010). Pseudomonas fluorescens orchestrates a fine metabolic-balancing act to counter aluminium toxicity. Environ. Microbiol. 12, 1384-1390. doi: 10.1111/j.14622920.2010.02200.x 
Lemire, J. A., Harrison, J. J., and Turner, R. J. (2013). Antimicrobial activity of metals: mechanisms, molecular targets and applications. Nat. Rev. Microbiol. 11, 371-384. doi: 10.1038/nrmicro3028

Ma, Z., Jacobsen, E., and Giedroc, P. (2009). Coordination chemistry of bacterial metal transport and sensing. Chem. Rev. 109, 4644-4681. doi: 10.1021/ cr900077w

Naik, M. M., Pandey, A., and Dubey, S. K. (2012). Biological characterization of lead-enhanced exopolysaccharide produced by a lead resistant Enterobacter cloacae strain P2B. Biodegradation 23, 775-783. doi: 10.1007/s10532-0129552-y

Nies, D. H. (1999). Microbial heavy-metal resistance. Appl. Microbiol. Biotechnol. 51, 730-750. doi: 10.1007/s002530051457

Nies, D. H., and Silver, S. (1995). Ion efflux systems involved in bacterial metal resistances. J. Ind. Microbiol. 14, 186-199. doi: 10.1007/BF01569902

Oves, M., Qari, H. A., Felemban, N. M., Khan, M. Z., Rehan, Z. A., and Ismail, I. M. I. (2017). Marinobacter lipolyticus from Red Sea for lipase production and modulation of silver nanomaterials for anti-candidal activities. IET Nanobiotechnol. 11, 403-410. doi: 10.1049/iet-nbt.2016.0104

Pal, A., and Paul, A. K. (2008). Microbial extracellular polymeric substances: central elements in heavy metal bioremediation. Indian J. Microbiol. 48, 49-64. doi: 10.1007/s12088-008-0006-5

Panda, T., and Deepa, K. (2011). Biosynthesis of gold nanoparticles. J. Nanosci. Nanotechnol. 11, 10279-10294. doi: 10.1166/jnn.2011.5021

Pérez, J. M., Calderón, I. L., Arenas, F. A., Fuentes, D. E., Pradenas, G. A., Fuentes, E. L., et al. (2007). Bacterial toxicity of potassium tellurite: unveiling an ancient enigma. PLoS One 2:e211. doi: 10.1371/journal.pone.0000211

Pugin, B., Cornejo, F., Muñoz, P., Muñoz, C., Vargas, J., Arenas, F., et al. (2014). Glutathione reductase-mediated synthesis of tellurium-containing nanostructures exhibiting antibacterial properties. Appl. Environ. Microbiol. 80, 7061-7070. doi: 10.1128/AEM.02207-14

Rao, J. (2008). Shedding light on tumors using nanoparticles. ACS Nano. 2, 1984-1986. doi: 10.1021/nn800669n

Reinoso, C. A., Auger, C., Appanna, V. D., and Vásquez, C. C. (2012). Telluriteexposed Escherichia coli exhibits increased intracellular $\alpha$-ketoglutarate. Biochem. Biophys. Res. Commun. 421, 721-726. doi: 10.1016/j.bbrc.2012. 04.069

Sandoval, J. M., Arenas, F. A., García, J. A., Díaz-Vásquez, W. A., ValdiviaGonzález, M., Sabotier, M., et al. (2015). Escherichia coli 6-phosphogluconate dehydrogenase aids in tellurite resistance by reducing the toxicant in a NADPHdependent manner. Microbiol. Res. 177, 22-27. doi: 10.1016/j.micres.2015. 05.002

Scott, D., Toney, M., and Muzikár, M. (2008). Harnessing the mechanism of glutathione reductase for synthesis of active site bound metallic nanoparticles and electrical connection to electrodes. J. Am. Chem. Soc. 130, 865-874. doi: $10.1021 /$ ja074660g

Shaw, C. F. (1999). Gold-based therapeutic agents. Chem. Rev. 99, 2589-2600. doi: $10.1021 /$ cr980431o

Silver, S., and Phung, L. (1996). Bacterial heavy metal resistance: new surprises. Annu. Rev. Microbiol. 50, 753-789. doi: 10.1146/annurev.micro.50.1.753

Silver, S., and Phung, L. (2005). A bacterial view of the periodic table: genes and proteins for toxic ions. J. Ind. Microbiol. Biotechnol. 32, 587-605. doi: 10.1007/ s10295-005-0019-6

Smith, W. L., and Gadd, G. M. (2000). Reduction and precipitation of chromate by mixed culture sulphate-reducing bacterial biofilms. J. Appl. Microbiol. 88, 983-991. doi: 10.1046/j.1365-2672.2000.01066.x

Snyder, R. M., Mirabelli, C. K., and Crooke, S. T. (1986). Cellular association, intracellular distribution, and efflux of auranofin via sequential ligand exchange reactions. Biochem. Pharmacol. 35, 923-932. doi: 10.1016/0006-2952(86) 90078-X

Stadtman, E. R., and Levine, R. L. (2000). Protein oxidation. Ann. N. Y. Acad. Sci. 899, 191-208. doi: 10.1111/j.1749-6632.2000.tb06187.x
Stephen, J. R., and Macnaughton, S. J. (1999). Developments in terrestrial bacterial remediation of metals. Curr. Opin. Biotechnol. 10, 230-233. doi: 10.1016/S09581669(99)80040-8

Summers, A., and Silver, S. (1978). Microbial transformations of metals. Annu. Rev. Microbiol. 32, 637-672. doi: 10.1146/annurev.mi.32.100178.003225

Suresh, A. K. (2012). Metallic Nanocrystallites and Their Interaction with Microbial Systems. Berlin: Springer Science. doi: 10.1007/978-94-007-4231-4

Taylor, D. E. (1999). Bacterial tellurite resistance. Trends Microbiol. 7, 111-115. doi: 10.1016/S0966-842X(99)01454-7

Thakkar, K., Mhatre, S., and Parikh, R. (2010). Biological synthesis of metallic nanoparticles. Nanomedicine 23, 257-262. doi: 10.1016/j.nano.2009.07.002

Touati, D., Jacques, M., Tardat, B., Bouchard, L., and Despied, S. (1995). Lethal oxidative damage and mutagenesis are generated by iron in $\Delta$ fur mutants of Escherichia coli: protective role of superoxide dismutase. J. Bacteriol. 177, 2305-2314. doi: 10.1128/jb.177.9.2305-2314.1995

Trutko, S. M., Akimenko, V. K., Suzina, N. E., Anisimova, L. A., Shlyapnikov, M. G., Baskunov, B. P., et al. (2000). Involvement of the respiratory chain of gramnegative bacteria in the reduction of tellurite. Arch. Microbiol. 173, 178-186. doi: $10.1007 / \mathrm{s} 002039900123$

Turner, R., Weiner, J., and Taylor, D. (1999). Tellurite-mediated thiol oxidation in Escherichia coli. Microbiology 145, 2549-2557. doi: 10.1099/00221287-145-92549

Turner, R. J., Borghese, R., and Zannoni, D. (2012). Microbial processing of tellurium as a tool in biotechnology. Biotechnol. Adv. 30, 954-963. doi: 10.1016/ j.biotechadv.2011.08.018

van Hullebusch, E. D., Zandvoort, M. H., and Lens, P. N. (2003). Metal immobilisation by biofilms: mechanisms and analytical tools. Rev. Environ. Sci. Biotechnol. 2, 9-33. doi: 10.1023/B:RESB.0000022995.48330.55

Vlamis-Gardikas, A. (2008). The multiple functions of the thiol-based electron flow pathways of Escherichia coli: eternal concepts revisited. Biochim. Biophys. Acta 1780, 1170-1200. doi: 10.1016/j.bbagen.2008.03.013

Vrionis, H. A., Wang, S., Haslam, B., and Turner, R. J. (2015). Selenite protection of tellurite toxicity toward Escherichia coli. Front. Mol. Biosci. 2:69. doi: 10.3389/ fmolb.2015.00069

Wingender, J., Neu, T. R., and Flemming, H. C. (1999). "What are bacterial extracellular polymeric substances?", in Microbial Extracellular Polymeric Substances, eds J. Wingender, T. R. Neu, and H. C. Flemming (Berlin: Springer), doi: 10.1007/978-3-642-60147-7_1

Xiong, Y., and Lu, X. (2015). Metallic Nanoestructures: From Controlled Synthesis to Applications. Cham: Springer International publishing.

Xiu, Z. M., Zhang, Q. B., Puppala, H. L., Colvin, V. L., and Alvarez, P. J. (2012). Negligible particle-specific antibacterial activity of silver nanoparticles. Nano Lett. 12, 4271-4275. doi: 10.1021/nl301934w

Zannoni, D., Borsetti, F., Harrison, J. J., and Turner, R. J. (2007). The bacterial response to the chalcogen metalloids Se and Te. Adv. Microb. Ecol. 53, 1-71. doi: 10.1016/S0065-2911(07)53001-8

Zare, B., Babaie, S., Setayesh, N., and Shahverdi, A. R. (2013). Isolation and characterization of a fungus for extracellular synthesis of small selenium nanoparticles. Nanomedicine 1, 13-19. doi: 10.7508/nmj.2013.01.002

Conflict of Interest Statement: The authors declare that the research was conducted in the absence of any commercial or financial relationships that could be construed as a potential conflict of interest.

Copyright (c) 2018 Contreras, Vargas, Jiménez, Muñoz-Villagrán, Figueroa, Vásquez and Arenas. This is an open-access article distributed under the terms of the Creative Commons Attribution License (CC BY). The use, distribution or reproduction in other forums is permitted, provided the original author(s) and the copyright owner(s) are credited and that the original publication in this journal is cited, in accordance with accepted academic practice. No use, distribution or reproduction is permitted which does not comply with these terms. 